\title{
Neuromuscular Activity Blockade Induced by Muscimol and $d$-Tubocurarine Differentially Affects the Survival of Embryonic Chick Motoneurons
}

\author{
Marianne F. Usiak and Lynn T. Landmesser \\ Department of Neurosciences, Case Western Reserve University, School of Medicine, Cleveland, Ohio 44106-4975
}

To understand better how spontaneous motoneuron activity and intramuscular nerve branching influence motoneuron survival, we chronically treated chicken embryos in ovo with either $d$-tubocurarine (dTC) or muscimol during the naturally occurring cell death period, assessing their effects on activity by in ovo motility measurement and muscle nerve recordings from isolated spinal cord preparations. Because muscimol, a GABA agonist, blocked both spontaneous motoneuron bursting and that elicited by descending input but did not rescue motoneurons, we conclude that spontaneous bursting activity is not required for the process of normal motoneuron cell death. $d \mathrm{TC}$, which rescues motoneurons and blocks neuromuscular transmission, blocked neither spontaneous nor descending inputelicited bursting and early in the cell death period actually increased burst amplitude. These changes in motoneuron activation could alter the uptake of trophic molecules or gene transcription via altered patterns of $\left[\mathrm{Ca}^{2+}\right]_{i}$, which in turn could affect motoneuron survival directly or indirectly by altering intramuscular nerve branching. A good correlation was found between nerve branching and motoneuron survival under various experimental conditions: (1) dTC, but not muscimol, greatly increased branching; (2) the removal of PSA from NCAM partially reversed the effects of $\mathrm{dTC}$ on both branching and survival, indicating that branching is a critical variable influencing motoneuron survival; (3) muscimol, applied with dTC, prevented the effect of $d \mathrm{TC}$ on survival and motoneuron bursting and, to a large extent, its effect on branching. However, the central effects of $d \mathrm{TC}$ also appear to be important, because muscimol, which prevented motoneuron activity in the presence of $\mathrm{dTC}$, also prevented the $\mathrm{dTC}$-induced rescue of motoneurons.

Key words: motoneuron survival; cell death period; activity blockade; intramuscular nerve branching; muscimol; spontaneous burst activity
Chronic administration of $d$-tubocurarine ( $d \mathrm{TC})$, an acetylcholine receptor (AChR) antagonist, during development induces neuromuscular activity blockade and rescues motoneurons from naturally occurring cell death (Hamburger, 1975; Oppenheim and Chu-Wang, 1977; Pittman and Oppenheim, 1978). It also produces an increase in intramuscular nerve branching and synapse formation at the onset of the cell death period, leading to the suggestion that enhanced trophic factor uptake at these sites might play a critical role in their enhanced survival (Dahm and Landmesser, 1988, 1991; Oppenheim, 1989; Landmesser, 1992; Calderó et al., 1998). Previous work had shown that both $d$ TC and $\alpha$-bungarotoxin ( $\alpha \mathrm{BTX}$, another AChR antagonist) could block neuromuscular activity by acting not only at the neuromuscular junction (NMJ) but also by acting centrally within the spinal cord (Landmesser and Szente, 1986). High densities of the $\alpha 7$ nicotinic $\mathrm{AChR}$ are, in fact, present in the lateral motor column during the motoneuron cell death period (Renshaw et al., 1993; Renshaw and Goldie, 1996). Also supporting a site of action for $d$ TC other than the NMJ was the observation of Hory-Lee and Frank (1995)

\footnotetext{
Received Feb. 24, 1999; revised June 16, 1999; accepted June 25, 1999.

This work was supported by National Institutes of Health Grant NS19640 from the National Institute of Neurological Diseases and Stroke. We thank Drs. V. Rafuse, S. Banerjee, and L. Milner for helpful input during the course of this research as well as for critical reading of this manuscript. In addition, we thank Dr. Urs Rutishauser for the gift of the endosialidase-N.

Correspondence should be addressed to Dr. Lynn T. Landmesser, Department of Neurosciences, Case Western Reserve University, School of Medicine, Cleveland, OH 44106-4975.

Copyright (C) 1999 Society for Neuroscience $\quad 0270-6474 / 99 / 197925-15 \$ 05.00 / 0$
}

that subparalytic doses of $d \mathrm{TC}$ rescued motoneurons from cell death.

Thus, it is presently unclear whether $d$ TC rescues motoneurons from cell death by acting at central or peripheral sites or both. The increase in motoneuron survival could result from any combination of the following observed effects of $d$ TC: neuromuscular activity blockade (Oppenheim and Chu-Wang, 1977; Pittman and Oppenheim, 1978; Ding et al., 1983; Dahm and Landmesser, 1988), increases in intramuscular nerve branching and synaptogenesis (Ding et al., 1983; Dahm and Landmesser, 1988, 1991; Oppenheim, 1989; Landmesser, 1992), blockade of peripheral AChRs (postsynaptic AChRs at the NMJ or presynaptic ones on motoneuron axons), or blockade of central AChRs within the spinal cord (Landmesser and Szente, 1986; Renshaw et al., 1993; Renshaw and Goldie, 1996).

To test whether neuromuscular activity blockade per se was the critical feature of the $d \mathrm{TC}$ treatments that influenced motoneuron survival, we blocked activity in a manner that avoided any direct effects on nicotinic receptors. In the chick embryonic spinal cord, during the period of motoneuron cell death, GABAergic immunoreactive interneurons are present (Antal et al., 1994) and are an important component of the circuit that drives motoneurons in periodic bursts of electrical activity (Sernagor et al., 1995; Chub and O'Donovan, 1998). We found that application of the $\mathrm{GABA}_{\mathrm{A}}$ agonist muscimol blocked spontaneous motoneuron bursting in isolated spinal cord preparations and blocked spontaneous motility when it was applied in ovo. Thus, by acting on the circuitry within the spinal cord, possibly including motoneuron somas, muscimol indirectly blocks neuromuscular activity but does not 
act on nicotinic receptors at either the NMJ or in the spinal cord. In this study we compare the effects of $d$ TC versus muscimolinduced activity blockade on motoneuron survival and intramuscular nerve branching.

\section{MATERIALS AND METHODS}

White Leghorn fertile chick eggs (CWRU Squire Farm) were incubated in a humidified forced-air draft incubator at $38^{\circ} \mathrm{C}$ and used as described below. An opening was made in stage 23-25 (Hamburger and Hamilton, 1951) eggs, and the square hole subsequently was sealed with paraffin and a sterile coverslip.

Drug treatments. These began at stage (st.) 28-29, with the drug applied daily for $d$ TC ( $2 \mathrm{mg} / \mathrm{d}$; Sigma, St. Louis, MO) or twice a day for muscimol $(0.1 \mathrm{mg} / \mathrm{d}$; Sigma) and diluted in buffered Tyrode's solution [containing (in $\mathrm{mm}$ ) $139 \mathrm{NaCl}, 3 \mathrm{KCl}, 17 \mathrm{NaHCO}_{3}, 1 \mathrm{MgCl}$, and 3 $\mathrm{CaCl}_{2}$. These concentrations were used because they are just sufficient to block the motility of the hindlimb in ovo. The actual concentration of the drug in the embryo was estimated to be approximately $5 \times 10^{-6} \mathrm{M}$ for $d$ TC because this concentration was just sufficient to block transmission at the NMJ in the isolated cord preparation (see Fig. $1 g$ ). For muscimol, the estimated concentration was approximately $5 \times 10^{-6} \mathrm{M}$ because this concentration was also just sufficient to block spontaneous bursting in the isolated cord preparation (see Fig. 1a,b). Endosialidase-N (endo-N) was used and injected as previously described (Landmesser et al., 1990). Briefly, 0.1-1.0 $\mu \mathrm{l}$ of a highly purified solution of endo-N $(30,000 \mathrm{U} / \mathrm{ml}$; gift of Dr. Urs Rutishauser, Sloan-Kettering Institute, New York, NY) was injected with a glass micropipette into the dorsoposterior thigh on one side of a st. 26-27 embryo. A tracer dye, trypan blue in Tyrode's solution (sterile $0.04 \%$ trypan blue; Life Technologies, Grand Island, New York), was coinjected to ensure the location of the injection. Controls of dye and buffer injection alone showed no abnormalities when compared with noninjected embryos. Single localized injections of endo-N into the dorsal thigh were shown previously to remove polysialic acid (PSA) from the injected thigh for up to $3 \mathrm{~d}$ but not to affect the PSA levels in the contralateral limb or spinal cord (Landmesser et al., 1990).

The motility of the embryo after target innervation was observed as described previously (Dahm and Landmesser, 1988) by counting whole hindlimb movements (kicks) for a 3 min observation period, using a dissecting microscope focused through the hole in the egg onto the hindlimb. For $d \mathrm{TC}$ drug treatments the hindlimb movement blockade was observed as reported previously (Oppenheim, 1975; Dahm and Landmesser, 1988). For muscimol drug treatments, careful observations were made to characterize the precise motions of the hindlimb in both acute and chronic treatments and in both the isolated cord preparation and in ovo. The total number of embryos used included the following: for $d$ TC treatments, $n=108$ (mortality rate $=65 \%$ ); for muscimol, $n=119$ $($ mortality rate $=18 \%)$; for endo- $\mathrm{N}+d \mathrm{TC}, n=108$ (mortality rate $=$ $82 \%$ ); for endo-N, $n=28$ (mortality rate $=25 \%$ ); for muscimol $+d \mathrm{TC}$, $n=20$ (mortality rate $=30 \%$ ). The mortality rate with muscimolinduced chronic activity blockade was consistently much lower than the relatively high rate that we and others have found with $d \mathrm{TC}$. The reasons for this are unclear but might arise because $d \mathrm{TC}$ would act at multiple sites, including autonomic ganglia. In the present study it appeared that muscimol reduced the mortality rate caused by $d \mathrm{TC}$. However, the $d \mathrm{TC}$-induced mortality rate varies enough from study to study that such a conclusion is not warranted at this time. Embryos were decapitated at the appropriate stage, placed in an oxygenated Tyrode's bath, and processed as described below for either whole mounts or for sectioning.

Muscle whole mounts. These were done as described previously (Dahm and Landmesser, 1988). Briefly, the iliofibularis (IFIB) muscle was exposed by the removal of all other posterior thigh muscles and connective tissue; it was fixed in ice-cold acetone for $5 \mathrm{~min}$, washed [wash = three times for $5 \mathrm{~min}$ in PBS $(1 \times \mathrm{PBS})]$, incubated with the C2 monoclonal antibody (against chick neurofilament) for $1-3 \mathrm{hr}$, and then washed again. Next, the muscle was fixed further in $3.7 \%$ formaldehyde, diluted in $1 \times$ PBS for $30 \mathrm{~min}$, and then washed in PBS for three times at $15 \mathrm{~min}$ each. Secondary antibody incubation was with goat anti-mouse IgGFITC (Sigma) overnight at $4^{\circ} \mathrm{C}$. After a wash, the IFIB was dissected completely from the hindlimb and mounted in 50\% glycerol/PBS with $0.03 \mathrm{mg} / \mathrm{ml} p$-phenylenediamine (Sigma). The immunofluorescence of the labeled intramuscular nerve branching was viewed and photographed on a Nikon Microphot microscope with an FITC cube at a total magnification of $100 \times$. To reconstruct the entire IFIB muscle, we made photographic montages from the individual pictures. Each montage of a muscle was photographed, and from that negative a print of the muscle was made. Then the print was scanned, using the Duophot scanner combined with Fotolook/Adobe Photoshop/Corel Draw for final figure labeling and scale bar placement.

Motoneuron quantification. This was done as previously described (Tanaka and Landmesser, 1986). St. 36 spinal cords were dissected and fixed in Bouin's solution, dehydrated in ethanol and xylene, and paraffinembedded. Serial $14 \mu \mathrm{m}$ sections were cut throughout the lumbosacral cord and then were stained with hematoxylin and eosin-orange G. Serial reconstruction of the spinal cord was done by noting the presence of the DRG and the lateral motor column (LMC) enlargement, which together allow for the identification of the lumbar (L1-L8) spinal cord. Criteria for counting cells as motoneurons included the size of the cell and its location in the LMC and the presence of a nucleus. Cell counts were made of every fifth section in both the left and right LMCs (for endo$\mathrm{N}$-treated embryos only the injected side was counted). The total cell number per LMC side was obtained by adding together all of the counted cells in each left or right LMC and multiplying the total number of cells by five. Averages of left and right LMC were made, and statistics were generated from these numbers. No corrections were made for double counting on the basis of the criteria stated in Abercrombie (1946), because only relative and not absolute values were needed for comparisons. Nuclear diameters were measured in each drug treatment, and no significant difference in nuclear size was found for any treatment when it was compared with control. Thus, the numbers used in the graphs that are presented reflect raw, uncorrected (Abercrombie, 1946) counts showing the average cell count in a LMC in any one treatment.

Physiological characterization of the effects of $\mathrm{d} T C$ and muscimol. The electrophysiology was done as described previously (Landmesser and O’Donovan, 1984; Landmesser and Szente, 1986; Rafuse et al., 1996). Control embryos were decapitated and immediately placed in chilled and oxygenated Tyrode's, and eviscerated; a ventral laminectomy was performed. Dissection was done to expose the appropriate hindlimb muscle as well as the muscle nerves. The isolated cord-hindlimb preparation was placed in $30^{\circ} \mathrm{C}$ Tyrode's to equilibrate for several hours until spontaneous bursting of regular intervals began. Either electromyogram (EMG) or neurogram recordings were done by placing fine tip suction electrodes (flame-pulled polyethylene tubing, PE-190; Clay Adams) onto the muscle or muscle nerve, respectively, and applying suction to develop a tight seal. Such recordings were usually stable over many hours because the tapered flexible tubing moved with any contraction-generated movement, and therefore there was no damage to the nerve or muscle. The absolute amplitude of these extracellular recordings, which generally ranged between 0.2 and $0.5 \mathrm{mV}$, will vary with the tightness of the seal and thus is not a meaningful parameter. However, once a stable recording is obtained, the relative amplitude of the response before and after drug treatment provides a good estimate of the number of axons being activated. In all cases in which we observed a drug to increase or decrease the amplitude of the EMGs or neurograms, the amplitude returned to pre-drug levels on washout of the drug. Direct activation of a motoneuron pool by cord stimulation resulted in compound action potentials caused by the synchronous activation of many axons; these compound action potentials were generally in the range of $5-20 \mathrm{mV}$ in amplitude. The signal was amplified, filtered at $10 \mathrm{~Hz}$ low-pass and $30 \mathrm{kHz}$ high-pass (Grass P15 AC preamplifier; Quincy, MA), displayed on an oscilloscope (Tektronix R5030; Beaverton, CO) and Gould chart recorder (Gould, Cleveland, $\mathrm{OH}$ ), and simultaneously recorded on a Vetter VCR (model $500 \mathrm{H}$; Rebersburg, PA). Stimulation of the exposed thoracic or lumbar spinal cord was delivered by a standard stimulator (Grass S88), which was isolated from ground with a photoelectric stimulus isolation unit (Grass PSIU6B). Subsequent analysis was done by digitizing the recorded segment of interest, using MaCADIOS ADPO (GW Instruments, Somerville, MA) and subsequently by using SuperScope II Software (GW Instruments) for analysis and figure generation, except for Figure $1 g$, which used DigiData 1200 Series Interface (Axon Instruments, Foster City, CA) and Axoscope 7 Software (Axon Instruments) for digitization and analysis and Microcal Origin 5 (Northampton, MA) for figure generation. To remove background noise, we low-pass HAM-filtered Figure $1, a, c$, and $f$, at $20 \%$ frequency cutoff at $200 \mathrm{~Hz}$ (low-pass filtering passes low frequencies and attenuates the high frequencies). HAM uses a hamming window, which implements a rough low-pass filter; its transfer function follows a $\sin (f) / f$ shape with a stopband $43 \mathrm{~dB}$ down from its pass band. The drugs muscimol and $d \mathrm{TC}$ used in the isolated cord preparation bath were obtained from Sigma. 


\section{RESULTS}

\section{Characterization of muscimol-induced blockade of activity}

During the naturally occurring cell death period (st. 30-36) a number of important developmental events occur (for review, see Hamburger, 1977; Oppenheim, 1991). First, just before the onset of motoneuron cell death at st. 30 (Hamburger, 1975), the motoneuron axons reach their target muscles in the hindlimb (Dahm and Landmesser, 1988). By st. 31, after the nerve has grown further into the muscle, pronounced visible movements of the hindlimb can be observed (Hamburger and Balaban, 1963; Hamburger et al., 1965; Hamburger, 1975; Bekoff et al., 1975) and are produced by bursts of spontaneous motoneuron activity. The latter can be quantified by using electrodes to record from muscles or from muscle nerves (Bekoff et al., 1975). Thus, at this early stage in the cell death period, neuromuscular synapses are present (Dahm and Landmesser, 1991) and functional (Landmesser, 1978b; O’Donovan and Landmesser, 1987). Previous studies showed that the in ovo application of $d \mathrm{TC}$, a nicotinic acetylcholine receptor antagonist, blocked or greatly reduced the frequency of hindlimb movements (Pittman and Oppenheim, 1978; Dahm and Landmesser, 1988). However, these observations did not reveal what effects $d$ TC may have had on the spontaneous bursting of motoneurons during the cell death period. To determine this, as well as to explore the importance of central versus peripheral activity blockade, we treated embryos either with $d \mathrm{TC}$ or with muscimol, a $\mathrm{GABA}_{\mathrm{A}}$ receptor agonist, and characterized the effects of these drugs on motoneuron activity and motoneuron survival. In these experiments we sought to understand how $d \mathrm{TC}$ was influencing increased motoneuron survival.

Before we used muscimol to block neuromuscular activity, it was necessary to ascertain optimal blocking concentrations and to characterize further its mode of action. To do this, we used an isolated spinal cord-hindlimb preparation (Landmesser and O'Donovan, 1984; Chub and O'Donovan, 1998) and recorded from either a hindlimb muscle (EMG) or a muscle nerve (neurogram). The isolated spinal cord preparation undergoes episodes of spontaneous bursting activity, with the number and length of the bursts within each episode varying with developmental stage (Fig. $1 a$; entire top trace $=$ an episode). The interval between each of these spontaneous bursting episodes increases with age. As shown in Figure $1 b$, the mean interval between episodes increased from $4.15 \pm 0.13$ min (mean \pm SD) at st. 30 to $12.12 \pm 3.45 \mathrm{~min}($ mean $\pm \mathrm{SD})$ at st. 32 and $12.6 \pm 3.14 \mathrm{~min}$ (mean \pm SD) at st. 34 . An episode of bursting activity also can be triggered by a single stimulus to cervical or thoracic spinal cord, which activates descending input to the lumbar motoneurons (Fig. 1c, top trace). Such triggered episodes are identical in all respects to those occurring spontaneously.

By directly stimulating spinal nerves and recording EMGs, we found that muscimol (up to $1 \times 10^{-5} \mathrm{M}$ ) did not block neuromuscular transmission (Fig. 1g). As shown in this st. 32 example, the compound action potential recorded from the muscle was not altered by the application of $5 \times 10^{-6} \mathrm{M}$ muscimol, but it was blocked by $5 \times 10^{-6} \mathrm{M} d \mathrm{TC}$, as expected. However, by recording directly from muscle nerves, we found that the bath application of $5 \times 10^{-6}$ M muscimol blocked spontaneous motoneuron bursting activity for up to $3 \mathrm{hr}$ (the longest time period tested) at all stages of the naturally occurring cell death period (Fig. 1a, lower trace, $b)$. Because this was the minimum dose that blocked activity in the isolated spinal cord preparation, we assume that a similar concentration was achieved when muscimol applied in ovo blocked hindlimb movement and that this concentration also would block the spontaneous bursting of the motoneurons in ovo.

Because descending input from the brainstem can drive motoneuron bursting in the isolated cord preparation (Sholomenko and O'Donovan, 1995) and presumably could be active in ovo, we determined whether muscimol also could block such elicited bursting. As shown in the example of a st. 32 embryo (Fig. 1c, lower trace), $5 \times 10^{-6} \mathrm{M}$ muscimol also prevented descending input from activating motoneurons throughout the cell death period.

GABAergic interneurons, acting primarily via $\mathrm{GABA}_{\mathrm{A}}$ receptors, have been shown to be an important component of the network of neurons within the lumbar cord that drives the motoneurons in spontaneous bursts (Chub and O'Donovan, 1998). It also is known that GABA can be excitatory as well as inhibitory at early stages of development (Wu et al., 1992; Owens et al., 1996; Rohrbough and Spitzer, 1996). Although muscimol clearly blocked spontaneous bursting and that elicited by descending input, we wanted to determine whether stimulating more locally within the lumbar spinal cord could still activate motoneurons either directly or indirectly. Thus, while recording from the femorotibialis muscle nerve in the presence of $5 \times 10^{-6} \mathrm{M}$ muscimol (Fig. 1d,e, upper traces), we found that stimulation at LS2, the region containing the femorotibialis motoneurons (Landmesser, 1978a,b), elicited a compound action potential with one or two peaks [second peak marked by asterisk(s)]. The first, shorter latency peak was attributable to direct activation of the motoneurons, because it persisted at $10 \mathrm{~Hz}$ stimulation (Fig. 1d, lower trace), a frequency that blocks synaptic transmission at this stage of development, and in the presence of low $\mathrm{Ca}^{2+}$ and high $\mathrm{Mg}^{2+}$ (Fig. 1e). The second, longer latency peak (marked with two asterisks) appears to be attributable to synaptic activation because it was blocked by $10 \mathrm{~Hz}$ stimulation (Fig. 1d, lower trace) and by low $\mathrm{Ca}^{2+}$ Tyrode's $\left(0.2 \mathrm{~mm} \mathrm{Ca}^{2+}\right.$ and $7 \mathrm{mM} \mathrm{Mg}^{2+}$; Fig. $\left.1 e\right)$.

Thus, although muscimol prevents the spontaneous bursting of motoneurons and the ability of such bursting to be elicited by descending input, motoneurons in the presence of muscimol still could be activated both directly and synaptically. These data, taken together, suggest that muscimol is acting centrally to block the network of local interneurons that drive motoneuron bursting (Sernagor et al., 1995; Chub and O'Donovan, 1998) and the ability of descending input to activate this network. Furthermore, motoneurons do not appear to be extremely depolarized or hyperpolarized, because they still can be activated synaptically or directly.

Having shown that muscimol can block activity in the isolated spinal cord preparation, we proceeded to test its effects in ovo. Earlier studies had shown that GABA reduced, whereas the $\mathrm{GABA}_{\mathrm{A}}$ antagonist bicuculline increased, spontaneous motility in ovo (Reitzel et al., 1979). Because we had ascertained that muscimol does not block the NMJ (Fig. 1g), any effects it has on motility should be attributable to alterations in motoneuron bursting episodes. In control embryos, hindlimb movements occur in episodes in which a series of strong and sustained kicks moves the limb over a considerable angle. We found that $0.1 \mathrm{mg} / \mathrm{d}$ per egg was the minimal dose needed to block such movements over a $24 \mathrm{hr}$ period. Such movements were reduced in number by $88 \%$ with respect to controls (for example at st. 34, controls exhibited a mean of 24 kicks per 3 min period vs only 3 kicks in muscimol-treated embryos). This level of reduction in movement is similar to that previously reported for $d \mathrm{TC}$, which reduced 


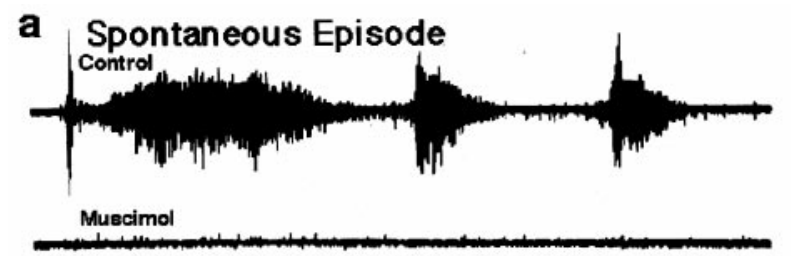

b

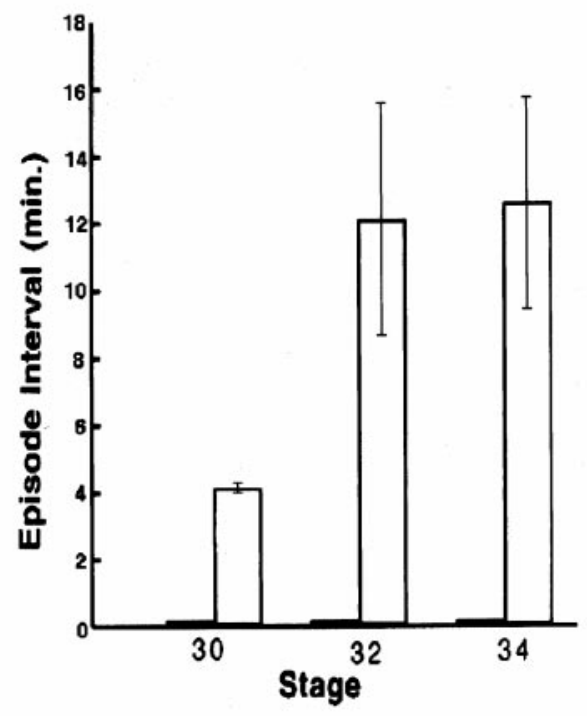

\section{f Spontaneous Episode}

St. 33

St. 31

\section{a 8}

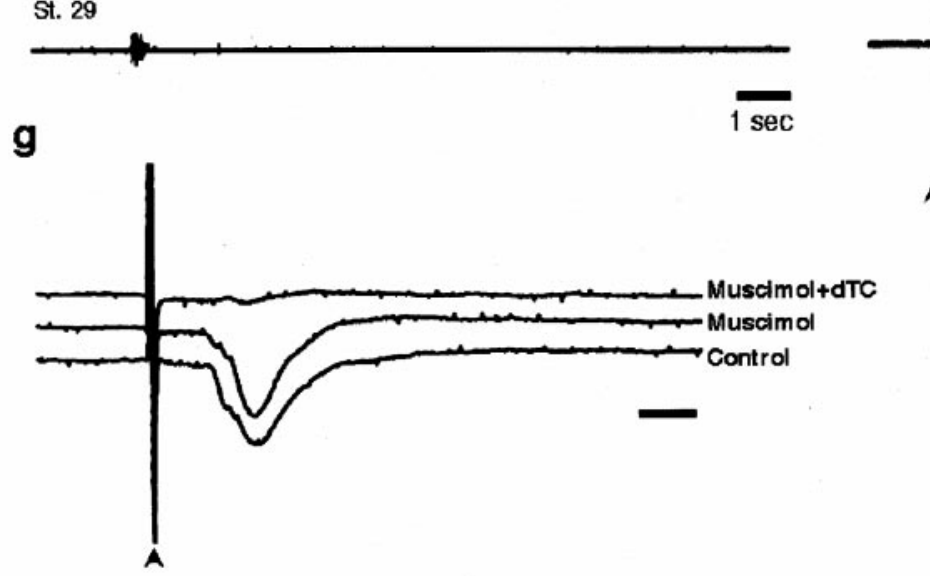

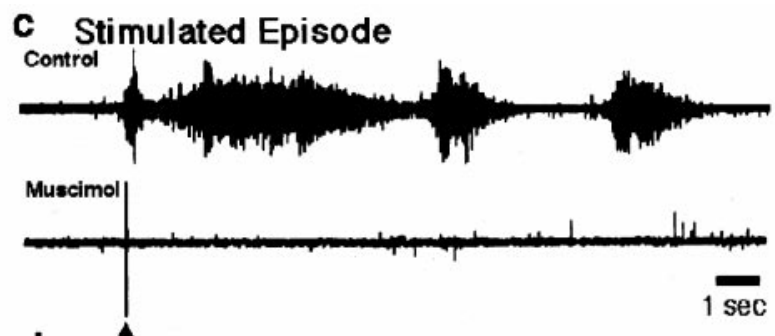
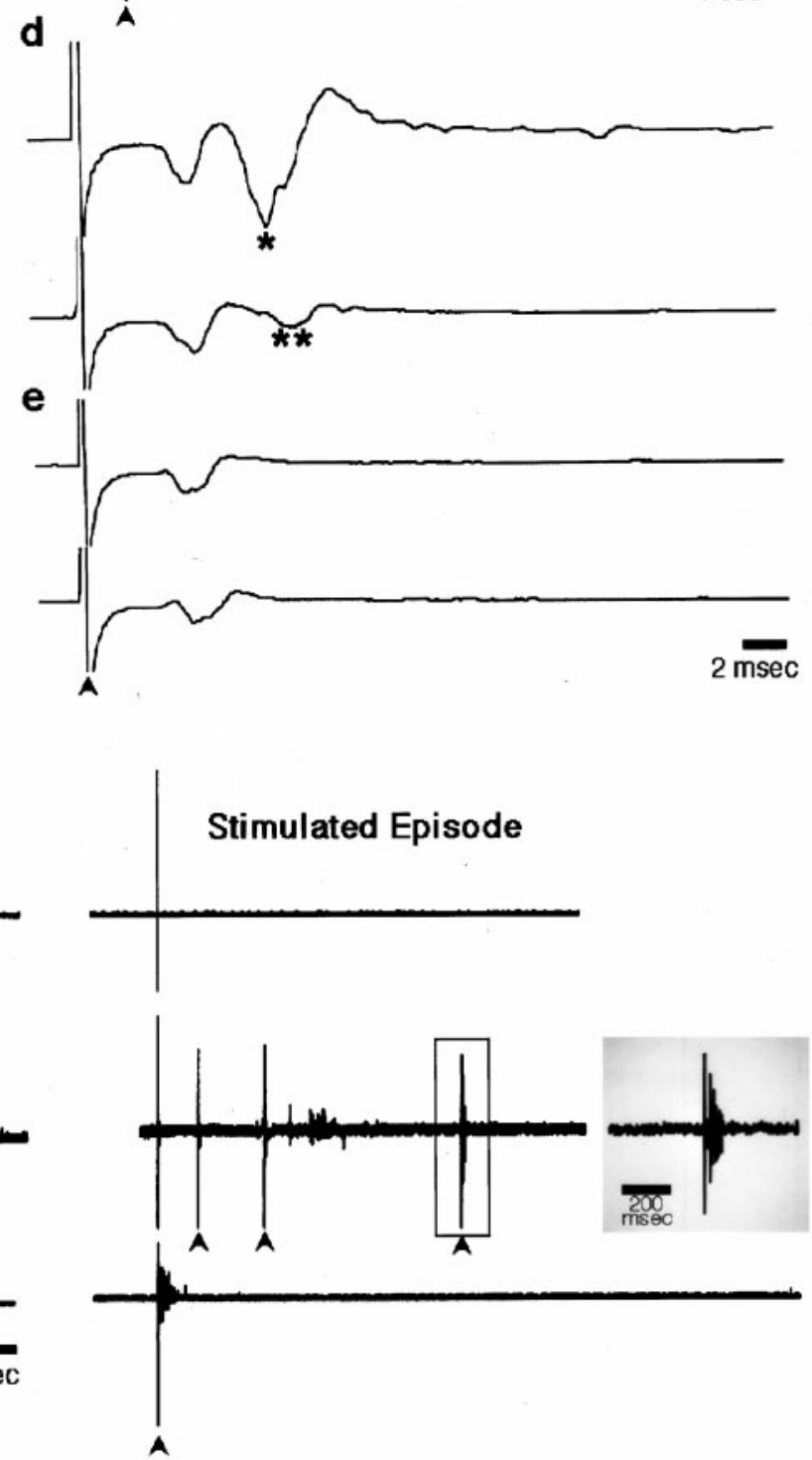

Figure 1. Characterization of the effects of muscimol: the acute $(a-e)$ and chronic $(f)$ effects of muscimol on motoneuron bursting in an isolated cord preparation. $a$, Neurogram recording from the femorotibialis muscle nerve of an episode of spontaneous bursting from a st. 32 chick embryo under control conditions (top trace) and in the presence of $5 \times 10^{-6} \mathrm{M}$ muscimol (bottom trace). Note the absence of any bursts. $b$, Mean time interval \pm SEM between spontaneous bursting episodes under control (open bars) and muscimol treatments (dark bars) at st. 30, 32, and 34 ( $n=7,6$, and 11, respectively). $c$, A single stimulus (arrowhead) to the cervical/thoracic spinal cord of a st. 32 chick embryo elicits a bursting episode before (Figure legend continues) 
movements by $82 \%$ from control levels (Pittman and Oppenheim, 1979). However, some brief low-amplitude movements persisted during chronic muscimol treatment, and we felt that it was important to determine whether these movements were produced by bursts of motoneuron activity or whether they simply represented the fibrillatory movements that occur when muscle is chronically paralyzed.

Because it is impossible to make in ovo muscle nerve recordings at these stages, we addressed this question by treating embryos chronically in ovo with muscimol, and then we dissected these embryos in the continuous presence of $5 \times 10^{-6} \mathrm{M}$ muscimol. Such chronically treated embryos did exhibit small, uncoordinated movements of different parts of the body, including the hindlimbs. However, these were not associated with motoneuron bursts as recorded from muscle nerves. Thus, many of the small movements observed in muscimol-treated embryos in ovo appear to be muscle-generated fibrillations and probably do not reflect motoneuron activity. By recording over periods of several hours we found that spontaneous bursting episodes were blocked in these embryos at stages encompassing most of the cell death period. As examples, in one st. 33 embryo and one st. 31 embryo (one midway through and one just after the onset of the cell death period, respectively) no spontaneous bursts occurred during the several hours of the recording period. However, in a st. 29 embryo (just before the cell death period), very short spontaneous bursts occurred with an irregular frequency of $10.7 \pm 6.04$ min (mean \pm $\mathrm{SD} ; n=8)$ in $5 \times 10^{-6} \mathrm{M}$ muscimol, although these were abolished when the muscimol concentration was increased to $1 \times$ $10^{-5} \mathrm{M}$. Because we cannot be certain of the in ovo muscimol concentrations, we cannot exclude the possibility that such brief bursts occurred in ovo at this young stage. However, as shown in Figure $1 f$, such episodes were extremely brief, one burst of $\sim 100-$ $200 \mathrm{msec}$, when compared with control-bursting episodes of similar stages (three bursts each of $2 \mathrm{sec}$; Fig. 1a). Thus, the in ovo muscimol treatments greatly reduced the overall amount of spontaneous bursting activity that motoneurons were exposed to when compared with controls or with $d \mathrm{TC}$-treated embryos, as described later.

The ability of descending input to generate bursting episodes also was greatly curtailed in these chronically treated embryos. At st. 33, no bursts could be elicited by stimulating descending input at cervical or rostrothoracic cord levels. At st. 31, as well, most stimuli failed to evoke bursts, although occasionally a very short single burst could be elicited, especially after repeated stimuli (see Fig. 1f, open gray box; solid gray box shows the burst elicited by the fourth stimulus on an expanded time scale). At st. 29, however, stimulation of the rostral cord, even in the higher dose $\left(1 \times 10^{-5} \mathrm{M}\right)$ of muscimol, was able to evoke single very brief

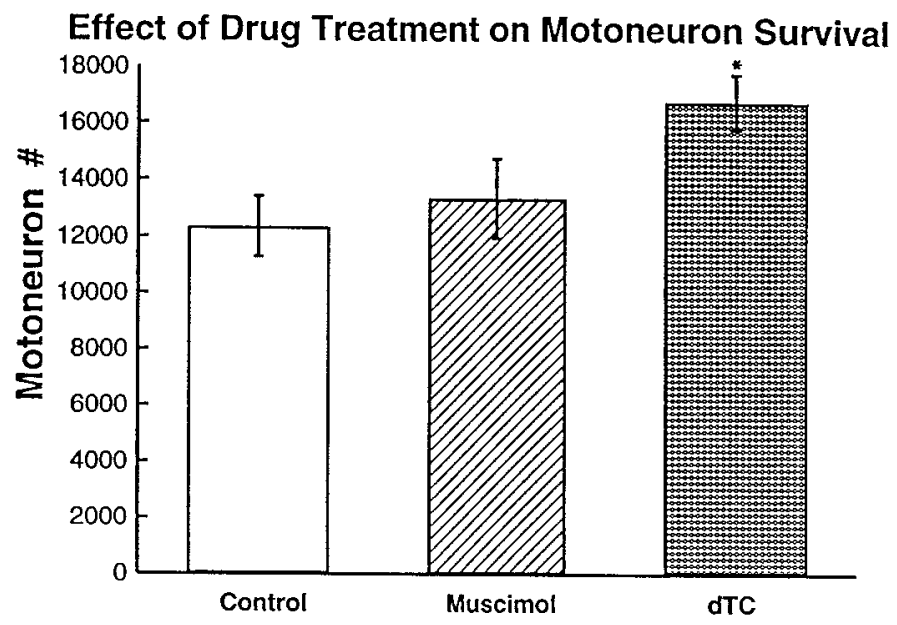

Figure 2. The number of motoneurons (on one side of the lumbar lateral motor column) surviving at the end of the naturally occurring cell death period after muscimol or $d$ TC-induced activity blockade. The number of motoneurons is significantly different from control after $d \mathrm{TC}$ treatment (*by $t$ test: $p=3.6 \times 10^{-5}$ for one-tailed and $p=7.2 \times 10^{-5}$ for two-tailed; $n=3$ for control and $d$ TC). The number of motoneurons after muscimol treatment is significantly fewer than that after $d$ TC treatment $(t$ test: $p=2 \times 10^{-4}$ for one-tailed and $p=4 \times 10^{-4}$ for two-tailed; $n=6$ for muscimol). Error bars represent SD.

bursts similar to those occurring spontaneously. Thus, if descending input is periodically active at this stage in ovo, it could elicit bursts, but, once again, the overall bursting activity during the cell death period should be greatly reduced.

\section{Effect of muscimol treatment on motoneuron survival}

Pittman and Oppenheim (1979) had shown that the blockade of neuromuscular activity by $d \mathrm{TC}$ during the cell death period resulted in an increase in motoneuron survival. We duplicated these results, finding that $d \mathrm{TC}$ increased cell survival $36 \%$ over controls (Fig. 2). However, blocking activity with muscimol during the same period did not increase motoneuron survival; motoneuron number after muscimol-induced activity blockade was not significantly different from control but was significantly less than the motoneuron number in the $d \mathrm{TC}$-treated embryos. This difference between muscimol and $d \mathrm{TC}$ treatments is interesting because, although both drug treatments block neuromuscular activity, motoneuron survival was increased only in the $d \mathrm{TC}$ treatment. Thus, although the blockade of muscle activation and contraction occurred in muscimol-treated embryos, this inactivity itself was not sufficient to alter cell survival. This suggests that there must be an effect of the $d \mathrm{TC}$ treatment, in addition to neuromuscular activity blockade, that affects cell survival.

(top trace), but not after (bottom trace), the application of $5 \times 10^{-6} \mathrm{M}$ muscimol. $d$, In the presence of $5 \times 10^{-6} \mathrm{M}$ muscimol, $1 / \mathrm{sec}$ stimulation of the motoneurons directly at LS2 elicits two peaks (top trace; single asterisk denotes second peak); the second peak (two asterisks), but not the first, fatigues with $10 \mathrm{~Hz}$ stimulation (bottom trace). $e$, In the presence of $5 \times 10^{-6} \mathrm{M}$ muscimol and low $\mathrm{Ca}^{2+}$ Tyrode's solution, $1 / \mathrm{sec}$ stimulation of the motoneurons directly at LS2 elicits one peak (top trace), which does not fatigue at $10 \mathrm{~Hz}$ stimulation (bottom trace); st. 32 chick embryo for $a, c, d$, and $e$. Calibration bars: $c$ (also applies to $a$ ), $1 \mathrm{sec} ; d, e, 2 \mathrm{msec}$. Gain for $d, e$, and $g$ is $5 \times$ that of $a-c$ and $f$. $f$, Effect of chronic muscimol treatment as follows: at st. 33 (top traces), no bursting activity occurred spontaneously nor could it be elicited by stimulation; at st. 31(middle traces), no bursting occurred spontaneously or after single stimuli. However, sometimes with multiple stimuli (arrowheads) a very short burst could be elicited, in this case after the fourth stimulus. This very short burst (enclosed in open gray box) is displayed on an expanded time scale at the end of the trace (shaded gray box). The very brief length of these bursts can be seen by comparing this trace with the control in $c$. At st. 29 (bottom traces) very brief bursts occurred spontaneously (left) and after stimulation of descending input (right). $g$, Effect of muscimol on synaptic transmission at the NMJ was assessed by recording the compound action potential elicited in a st. 29 sartorius muscle by stimulation (arrowhead) of the LS1 spinal nerve. Under both control conditions and in the presence of $5 \times 10^{-6} \mathrm{M}$ muscimol, the sartorius muscle exhibited a vigorous response. However, the addition of $5 \times 10^{-6} \mathrm{~m} d \mathrm{TC}$ blocked the postsynaptic muscle response. Calibration bar, $5 \mathrm{msec}$. 


\section{Effect of muscimol-induced activity blockade on intramuscular nerve branching}

Neuromuscular activity blockade induced by $d$ TC during the naturally occurring cell death period also results in an increase in intramuscular nerve branching. To compare the effects of $d \mathrm{TC}$ and muscimol on intramuscular nerve branching, we chose the iliofibularis (IFIB) muscle, in which the branching was quantified previously (Dahm and Landmesser, 1988). The IFIB has discrete regions that contain fast and slow myotubes (Fredette and Landmesser, 1991), which are innervated by distinct classes of motoneurons (Rafuse et al., 1996; Milner et al., 1998). The motoneuron axons that innervate the slow region have a characteristic collateral pattern of branching (shown in the st. 34 control muscle, Fig. 3a, solid bracket; magnified in $3 e, g$, $i$, and $k$ ), with the main nerve trunk growing parallel to the myotubes and small side branches exiting this main nerve trunk at right angles to both the myotubes and the main nerve trunk. The fast region (Fig. $3 a$, dashed bracket; magnified in $3 f, h, j$, and $l$ ) has a characteristic reductive pattern of branching, with the main trunk growing perpendicular to the myotubes and successively splitting into smaller branches (Dahm and Landmesser, 1988; Landmesser et al., 1990). Confirming previous observations (Dahm and Landmesser, 1988), we found that $d$ TC (Fig. $3 d$ ) treatment during the cell death period resulted in a profound alteration in the intramuscular nerve branching. Nerve trunks in both the fast (compare the fast magnified regions in Fig. $3 f, l$ ) and the slow regions (Fig. $3 e, l)$ were much more defasciculated than in the controls. In addition, the fast region was more highly branched (Fig. 3l), and many more side branches (arrows) emerged per unit length from the slow nerve trunks (compare the picture of the entire muscle, Fig. 3a,d; compare the slow magnified regions, Fig. $3 e, k$ ).

Interestingly, activity blockade induced by muscimol did not produce the same effect on intramuscular nerve branching as that induced by $d$ TC. With respect to the amount and pattern of branching, the muscimol-treated muscles were more similar to the control than to $d$ TC-treated muscles. As illustrated in the two examples shown in Figure 3, $b$ and $c$, muscimol treatment did not produce the extensive defasciculation that $d \mathrm{TC}$ did, especially in the fast region (compare Fig. 3h,j, with $l$ ). Although the overall branching pattern more closely resembled the controls, there clearly was some increase in the number of side branches in the slow region and probably an increase in side branch length (Fig. $3 g, i)$. However, branching was much less extensive than in the $d$ TC-treated muscle (Fig. $3 d$ ).

Within the muscimol-treated embryos there was a range in the effect of muscimol-induced activity blockade on branching; some, as in the example in Figure $3 b$, were quite similar to controls, whereas others (Fig. $3 c$ ) were somewhat more branched. Increasing the daily dose of the muscimol fourfold did not result in an increase in branching (data not shown), indicating that the range in response was probably not attributable to the in ovo muscimol concentrations being near a threshold for response. To see whether the embryos with more extensive intramuscular nerve branching (i.e., Fig. $3 c, i$ ) had higher levels of motoneuron survival, we made motoneuron counts from three such st. 36 embryos. No correlation was found ( $t$ test: one tail, $p=0.066$; two tail, $p=0.131)$.

Although the lack of a robust effect of muscimol on intramuscular nerve branching is consistent with the intramuscular nerve branching/trophic factor access hypothesis (Dahm and Landmesser, 1988, 1991; Oppenheim 1989; Landmesser, 1992), some increase in branching, especially in the slow region, did occur after muscimol treatment, with no correlated increase in motoneuron survival. Others have shown that subparalytic doses of $d \mathrm{TC}$ can rescue motoneurons from cell death with only moderate increases in intramuscular branching (Hory-Lee and Frank, 1995). This suggests that there is some unique aspect of the $d$ TC-induced increase in branching that results in motoneuron survival (i.e., such as the extensive defasciculation observed in both fast and slow regions with $d \mathrm{TC}$, but not with muscimol). This possibility could be evaluated once the downstream consequences of $d \mathrm{TC}$ treatment that actually rescue motoneurons (such as enhanced trophic factor uptake) are identified. Alternatively, $d$ TC could be affecting survival by an additional mechanism. If the critical effect of $d$ TC in promoting survival is via increased branching, then preventing this increase in the continued presence of $d \mathrm{TC}$ should negate the effect of $d \mathrm{TC}$ on survival and provide support for the access hypothesis. We tested this as described below.

\section{Effects of combined treatment with dTC and endo-N on intramuscular nerve branching}

The large increase in intramuscular nerve branching after $d \mathrm{TC}$ treatments was shown to be caused at least in part by an upregulation of PSA, a large carbohydrate added to neural cell adhesion molecule (NCAM) (Landmesser et al., 1990). NCAM, containing high levels of PSA, can act in a de-adhesive manner (Acheson et al., 1991), and the highly sialylated form of NCAM therefore can promote the defasciculation of axons within the muscle, resulting in increased intramuscular nerve branching (Landmesser et al., 1990). This increase in branching was hypothesized to facilitate trophic factor uptake, supporting increased motoneuron survival (Dahm and Landmesser, 1988). Therefore, the next series of experiments was designed to test whether the increased intramuscular branching produced by $d \mathrm{TC}$ was a critical variable in motoneuron survival. This was achieved by preventing the $d \mathrm{TC}$ induced increase in branching by the simultaneous application of $d \mathrm{TC}$ and endo-N. Endo-N, which removes PSA from NCAM, previously has been shown to reduce the amount of branching produced by $d$ TC (Landmesser et al., 1990; Tang and Landmesser, 1993).

It also was reported that chronic endo- $\mathrm{N}$ did not alter embryonic motility nor prevent the ability of descending input to elicit a normal bursting episode when it was acutely applied to an isolated cord preparation (Tang and Landmesser, 1993). However, that study did not record spontaneous bursting episodes from embryos chronically treated with endo-N.

Therefore, we first confirmed that chronic endo-N treatment did not alter spontaneous motility of the hindlimb, an indirect measure of motoneuron bursting. We counted the number of hindlimb movements per $3 \mathrm{~min}$ at st. 29, 30-31, 32-33, and 34 and found that, although there is a steep relationship between age and the total movements, at no stage were the counts for the endo$\mathrm{N}$-treated embryos statistically different from age-matched controls. For example, at st. 32-33 the endo-N-treated embryos exhibited $18.9 \pm 3.7$ versus $19.1 \pm 3.6 \mathrm{kicks}($ mean $\pm \mathrm{SD})$ for the controls.

In one case we made an isolated cord preparation from a st. 29 embryo that had been chronically treated with endo-N for $24 \mathrm{hr}$. As shown by the recording from the femorotibialis and sartorius nerves, such embryos exhibited spontaneous episodes with the normal number and pattern of bursts (see Fig. $5 a$; compare with control st. 29 embryo in Fig. 6c). In this endo-N-treated embryo 

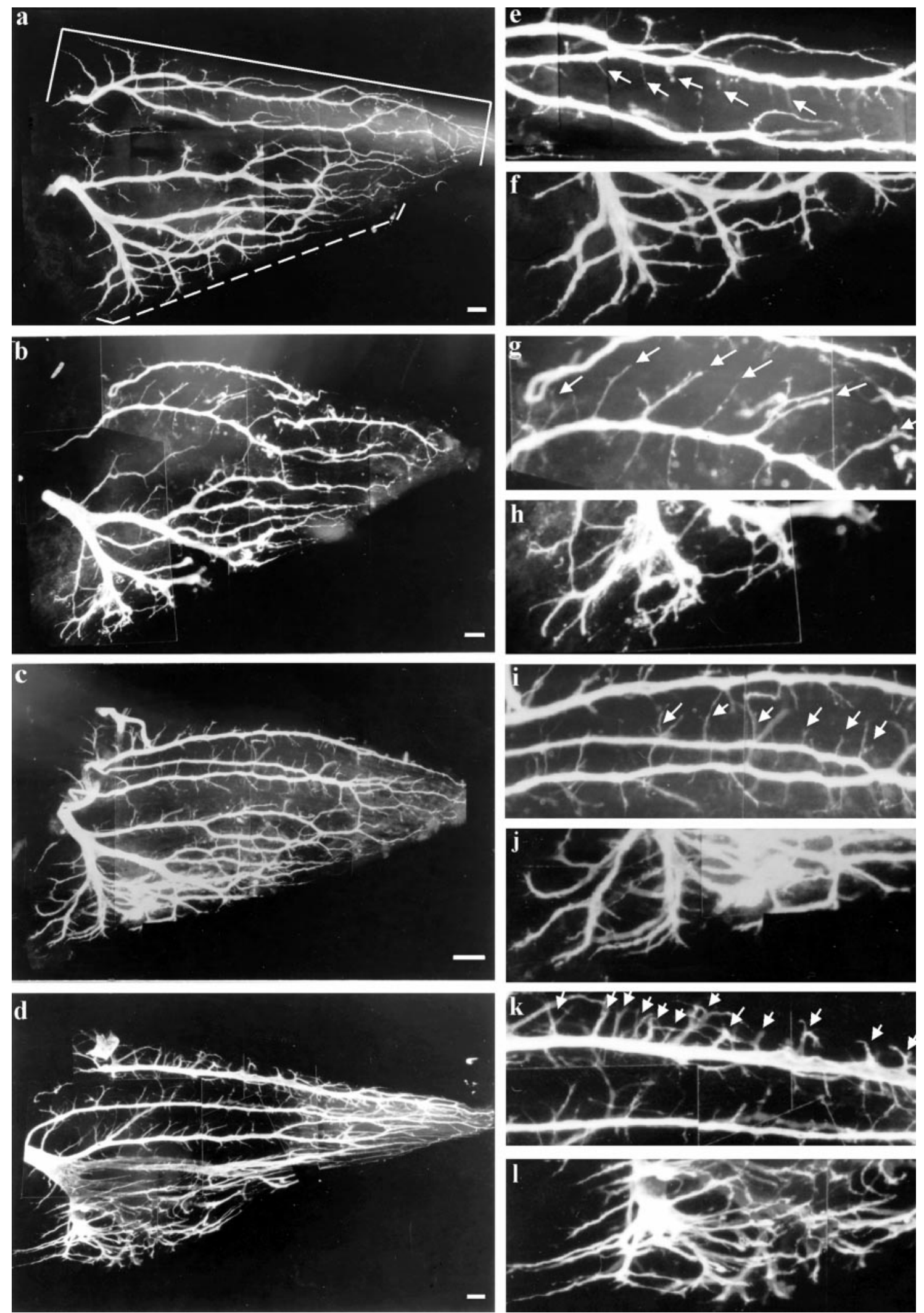

Figure 3. Whole mounts of a st. 34 chick IFIB muscle showing the intramuscular nerve branching pattern visualized by immunostaining for neurofilament, using the antibody $\mathrm{C} 2$. Left panels show whole muscle; right panels show portions of the slow (top) and the fast (bottom) regions of the muscle at higher magnification. $a$, Control; note the labeled fast (dashed bracket) and slow (solid bracket) regions. $b$, Muscimol-treated embryo resembles control but has longer side branches in the slow region. $c$, Another muscimol-treated embryo showing some increase in branching in both the fast and the slow region, but not as much as that shown in $d$ for $d \mathrm{TC}$. $\mathrm{d}, d \mathrm{TC}$-treated embryo; note the high frequency of side branches (arrows) in the slow region and the extensive defasciculation and branching in the fast region. $e$, $f$, Magnification of the control (shown in a); note the (Figure legend continues) 
the mean interepisode interval of $7.32 \pm 0.8$ min $($ mean $\pm \mathrm{SD})$ differed slightly from that of a control embryo at this stage, $5.6 \pm$ 2.1 min (mean $\pm \mathrm{SD}$ ), but such variation is within that expected because of the steep relationship between developmental stage and motility.

Endo-N, applied during the in ovo dTC treatment (st. 29-36), removed PSA as ascertained by immunostaining at multiple time points during the cell death period (data not shown). In most of the embryos that were observed from st. 28 to 36, immunofluorescent labeling for PSA was absent, whereas simultaneous immunofluorescence for the cell adhesion molecule L1 was positive in all sections $(n=11)$. Only one of these embryos, at st. 34 , had some positive staining for PSA. Thus, removal of PSA from the injected thigh was achieved during the critical time period when most motoneurons are committing to live or die.

The dual treatment with endo- $\mathrm{N}$ and $d \mathrm{TC}$ resulted in less extensive branching than $d \mathrm{TC}$ treatment alone. Figure $4 a$ shows the control IFIB branching pattern in a st. 34 embryo. Treatment with endo-N alone reduced branching in both the fast and slow regions (Fig. 4b). $d \mathrm{TC}$ treatment alone (Fig. 4d) produced the large increase in branching that was described previously. However, the addition of endo-N to $d \mathrm{TC}$ (Fig. $4 c$ ) resulted in a clear decrease in branching in both the fast (compare dashed bracket area, Fig. $4 c, d$ ) and slow regions when compared with $d$ TC treatment alone. Thus, endo- $\mathrm{N}$ was able to partially prevent the $d \mathrm{TC}$-induced increase in branching, even under the conditions of activity blockade. However, such dually treated muscles still had more nerve branching in both the fast and the slow regions than did the control muscles (compare Fig. $4 c$ with $a$ ). Figure 4 shows examples of whole mounts from st. 34 embryos near the middle of the cell death period, and these are representative of others done at earlier and later stages.

\section{The effect of combined $\mathrm{dTC}$ and endo- $\mathrm{N}$ treatment on motoneuron survival}

Motoneuron counts at st. 36, the end of the cell death period, after the dual $d$ TC and endo-N treatment are shown in Figure $5 b$. These results show that the increased motoneuron survival produced by $d$ TC was reduced significantly by simultaneous treatment with endo-N. As shown previously (Tang and Landmesser, 1993), endo-N alone was able to reduce survival significantly when compared with controls, although the effect in the present experiments was modest (i.e., a $10 \%$ reduction). As shown in Figure $5 b$ for the dual treatment, although $d \mathrm{TC}$ was present and able to act at both peripheral and central sites, the presence of endo-N was able to reduce motoneuron survival toward control levels.

Thus, the combined treatment of $d \mathrm{TC}$ and endo- $\mathrm{N}$ reduced both intramuscular nerve branching and motoneuron survival to a value in between the control and the $d$ TC-treated embryos. This is consistent with the idea that the degree of intramuscular branching can affect motoneuron survival, perhaps via trophic uptake at the NMJ (Dahm and Landmesser, 1988; DiStefano et al., 1992). However, these data do not exclude the possibility that $d \mathrm{TC}$ also could affect motoneuron survival by acting directly on motoneurons. Thus, we determined whether $d \mathrm{TC}$ had any effects on the spontaneous bursting episodes at different stages during the cell death period.

\section{Effects of $d$ TC on motoneuron bursting activity}

Previous work, characterizing the effects of $d \mathrm{TC}$ at the end of the naturally occurring cell death period (st. 36), had shown that $d \mathrm{TC}$, either applied chronically from st. 30 in ovo or applied acutely to the isolated spinal cord preparation, could block the patterned bursting activity evoked by stimulation of the cervical spinal cord (Landmesser and Szente, 1986). The blocking effect of chronically applied $d$ TC was reversed by washing for $1-6 \mathrm{hr}$, indicating that the cord circuitry responsible for generating bursting activity was not damaged by the chronic in ovo $d \mathrm{TC}$ treatment. Although $d$ TC blocked stimulated bursting activity at st. 36, it was not known how $d \mathrm{TC}$ would affect stimulated or spontaneous bursting activity at earlier stages, especially during this period of naturally occurring cell death. Thus, we first characterized the effects of $d$ TC applied acutely to the isolated cord preparation on both stimulated and spontaneous bursting activity at earlier time points.

At st. 29, just before the onset of the cell death period, $d$ TC transiently suppressed spontaneous bursting, as illustrated in Figure $6 a$, in which the interval between episodes of spontaneous bursting is plotted as a function of time. Before $d$ TC application, the mean interval between episodes was $5.6 \pm 2.1$ min (mean \pm $\mathrm{SD} ; n=10)$. The application of $5 \times 10^{-6} \mathrm{M} d \mathrm{TC}$ suppressed bursting for $48 \mathrm{~min}$. However, bursting episodes then resumed, but at a lower frequency (the interval between episodes being $14.4 \pm 1.3 \mathrm{~min}$; mean $\pm \mathrm{SD} ; n=9$ ). This recovery of spontaneous bursting in the continued presence of drug appears to reflect plasticity in the early cord circuits that are capable of using several transmitter systems to drive spontaneous bursting. Because the details of this phenomenon are not germane to the present paper, they will not be considered further, but they have been characterized elsewhere (Chub and O'Donovan, 1998; Milner and Landmesser, 1999).

In addition to affecting the frequency of spontaneous bursting episodes, $d$ TC also altered the structure of the bursts (a single burst is bracketed in Fig. 6c, upper trace) within an episode. This effect, as well as the effects on spontaneous bursting, were highly dependent on developmental stage. For example, at st. 28-28.5, $5 \times 10^{-7} \mathrm{M} d \mathrm{TC}$ increased the number of bursts per episode and increased the amplitude and length of the individual bursts, especially for extensors such as the femorotibialis (see, for example, Fig. 7). By st. 29 (Fig. 6c), this enhancement was less pronounced; for example, the last burst in the three burst sequence, which is characteristic of st. 29, usually did not occur or was greatly diminished (Fig. $6 c$, arrows) in the presence of $5 \times 10^{-6}$ $\mathrm{M} d \mathrm{TC}$. However, the earlier bursts were still enhanced in amplitude.

Somewhat later during the cell death period, st. 32, the same concentration of $d \mathrm{TC}\left(5 \times 10^{-6} \mathrm{M}\right)$ had a much greater effect on

\section{$\leftarrow$}

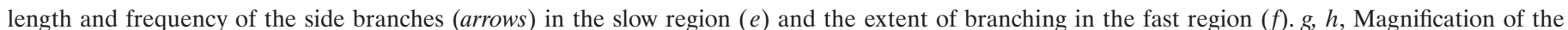

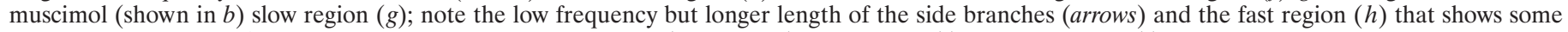

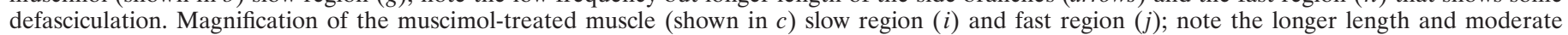

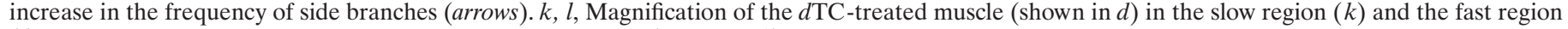

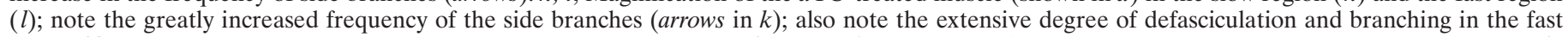

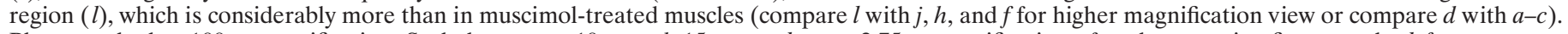
Photographed at $100 \times$ magnification. Scale bars: a-c, $10 \mu \mathrm{m} ; d, 15 \mu \mathrm{m} . e-l$ are a $2.75 \times$ magnification of each respective figure to the left. 

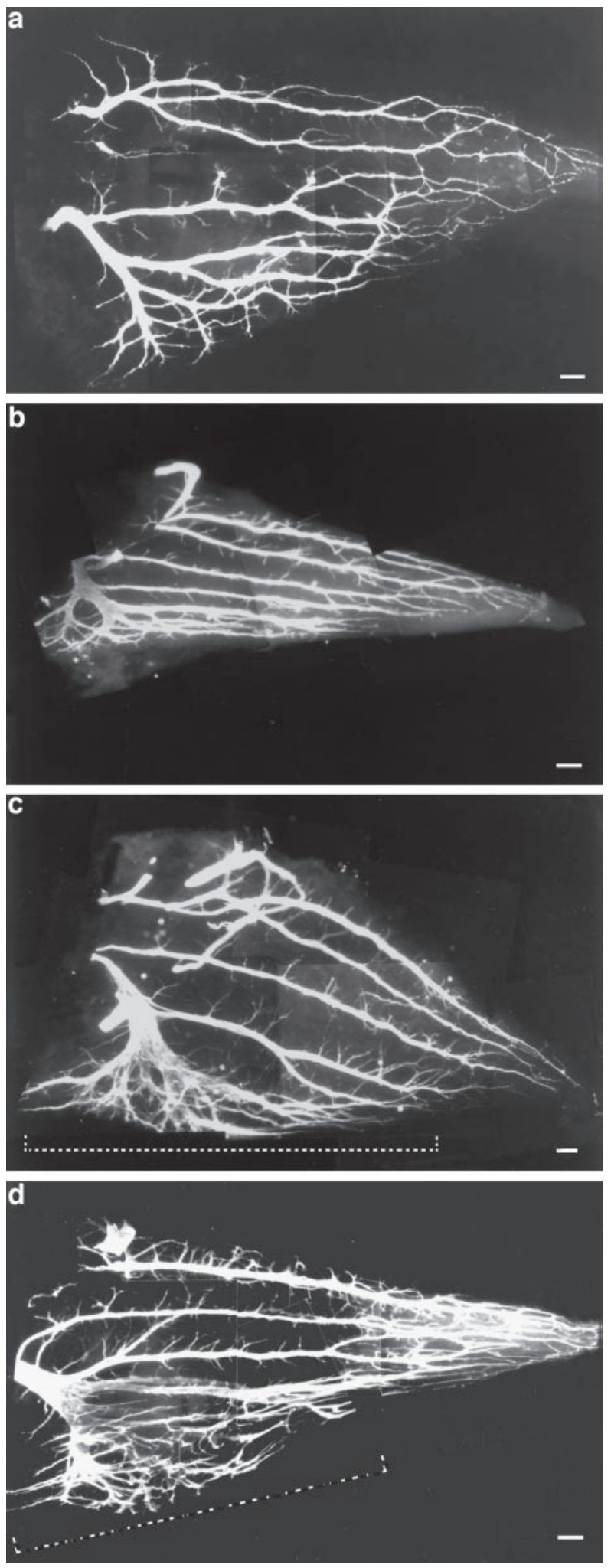

Figure 4. Whole mounts of st. 34 IFIB muscles showing the intramuscular nerve branching pattern, using $\mathrm{C} 2$ immunoreactivity. $a$, Control. $b$, Endo-N treatment, showing very fasciculated branches; although this muscle appeared slightly smaller than the control, this is within the range found in the controls. $c$, Endo-N plus $d \mathrm{TC}$; note the decrease in defasciculation and branching in the fast region (bracket) and a decrease in branching in the slow region when compared with $d \mathrm{TC}$ treatment alone. $d, d$ TC treatment alone (photographed at $100 \times$ magnification). Dashed brackets indicate the fast region. Scale bars: $a, b, d, 10 \mu \mathrm{m} ; c, 5 \mu \mathrm{m}$. a

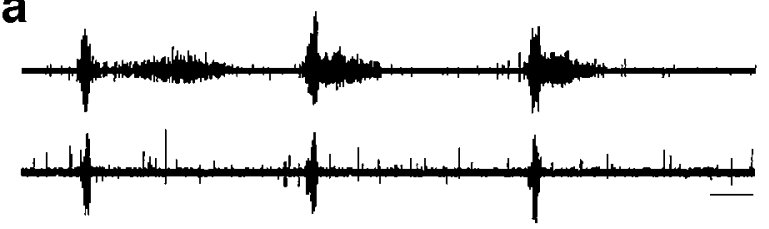

b

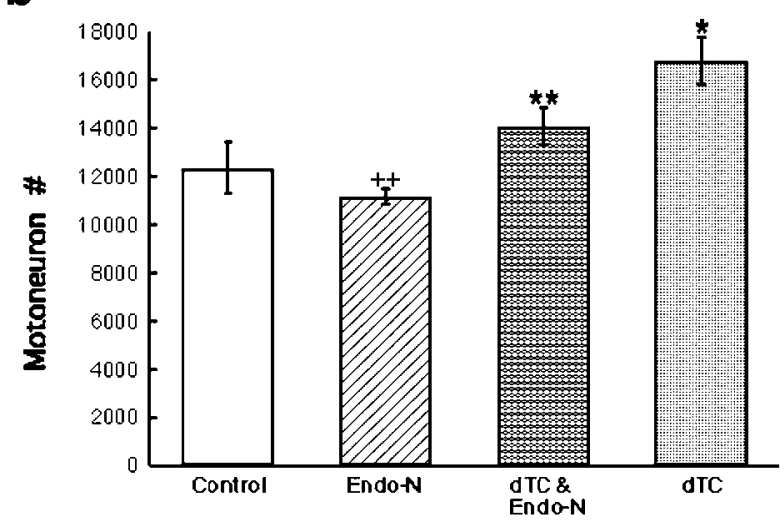

Figure 5. a, Neurogram recording from a chronically endo-N-treated embryo showing a spontaneous bursting episode. Top trace, femorotibialis. Bottom trace, sartorius. Calibration bar, $1 \mathrm{sec} . b$, Motoneuron counts from the lumbar lateral motor column at st. 36 after treatment with endo- $\mathrm{N}, d \mathrm{TC}$, or both together. $d \mathrm{TC}(*)$ is significantly different from control (see Fig. 2 legend). $d$ TC plus endo-N $(* *)$ is significantly different from $d$ TC treatment alone by two-tailed $t$ test, $p=8.62 \times 10^{-3}$ (one tail) and $p=0.0172$ (two tail) but also significantly different from control by two-tailed $t$ test, $p=0.0291$ (one tail) and $p=0.0583$ (two tail). Endo-N treatment alone $\left({ }^{++}\right)$is not significantly different from control by twotailed test, $p=0.0309$ (one tail) and $p=0.0618$ (two tail), but it is significantly different from the combined $d$ TC plus endo-N by two-tailed $t$ test, $p=0.0182$ (one tail) and $p=0.0364$ (two tail).

suppressing spontaneous bursting (Fig. 6b). At this stage the interval between bursting episodes in controls had increased to $8.2 \pm 3.03 \mathrm{~min}($ mean $\pm \mathrm{SD} ; n=8)$. After the application of $d \mathrm{TC}$, only one spontaneous burst occurred in $1.5 \mathrm{hr}$. However, even in the presence of $d \mathrm{TC}$, a bursting episode could be elicited reliably by single stimuli to the brachial or thoracic cord to activate descending input (Fig. 6d, lower two traces; arrowhead indicates stimulus). In this embryo, two bursts (indicated by brackets) were elicited per episode, and the characteristic differences between the femorotibialis (top trace) and the sartorius (bottom trace) had begun to emerge (O'Donovan and Landmesser, 1987). For example, the sartorius burst exhibits an inhibitory period (solid bar) at the onset of each burst, whereas the femorotibialis does not. Although these characteristic differences were still observed in the presence of $d \mathrm{TC}$ (Fig. $6 d$, bottom pair of traces), the overall length of the bursting episode was shortened, as if the episode had been compressed in time. Additionally, the femorotibialis did not become quiescent between bursts (gray shaded bar), as in controls, and the sartorius also exhibited higher activation between bursts.

These results show that $d \mathrm{TC}$ has strong effects on the cord circuitry responsible for spontaneous bursting, affecting both the circuit responsible for the timing of spontaneous episodes as well as that which regulates the burst structure. On the one hand, $d \mathrm{TC}$ appears to result in a stronger activation of the motoneuron pool during each episode, especially for the extensors such as the femorotibialis. Enhanced central activation of motoneurons in 
a

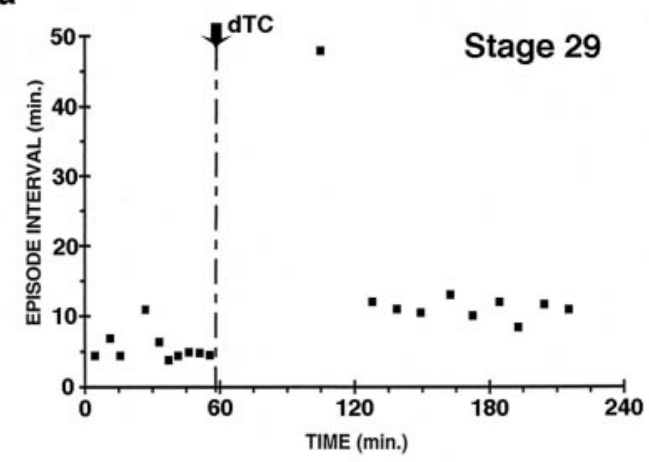

C

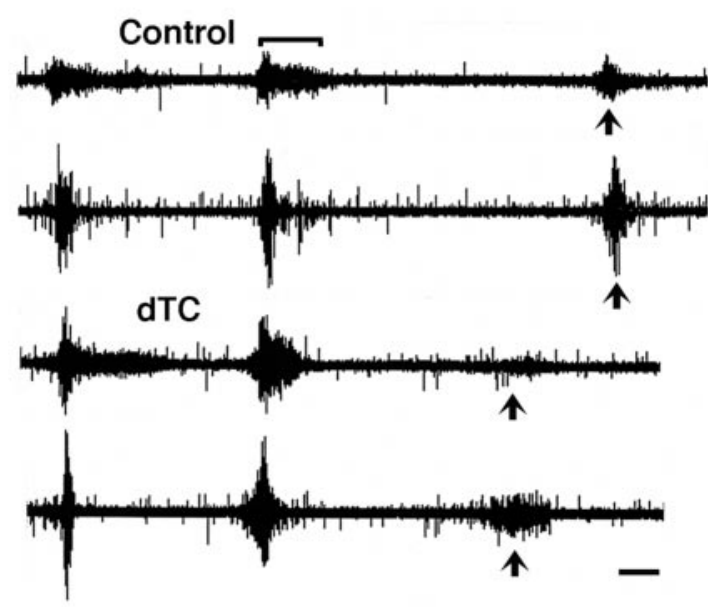

e
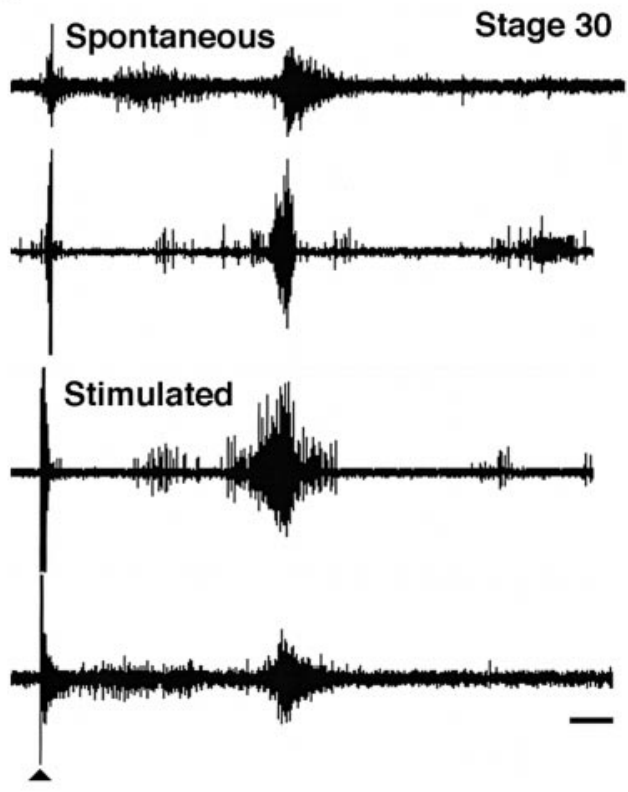

b

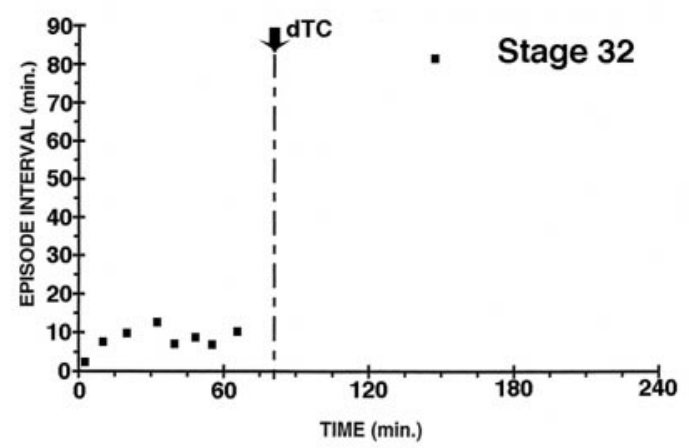

d
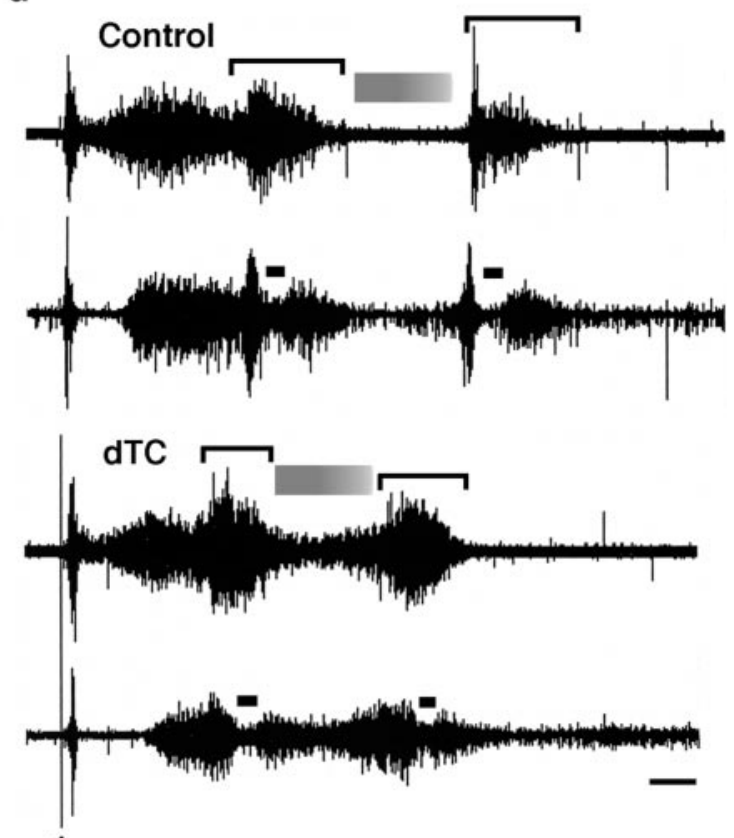

f

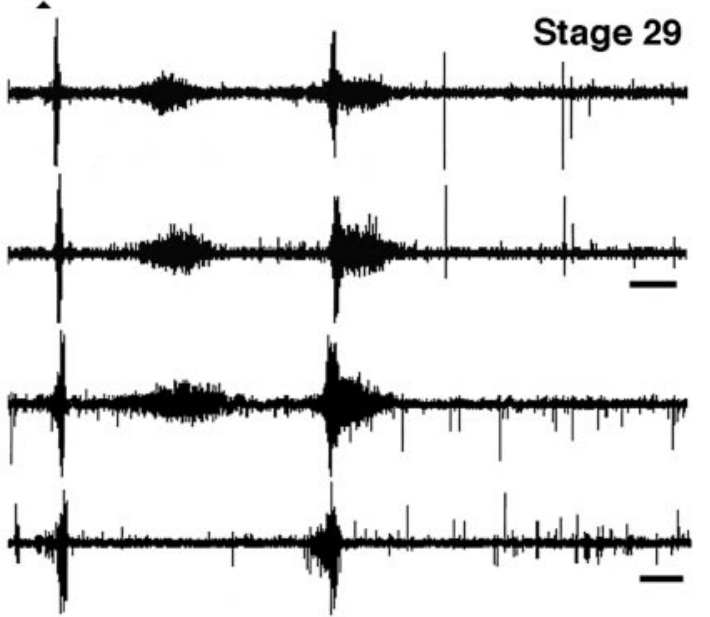

Figure 6. Recording from muscle nerves in isolated spinal cord preparations treated acutely ( $a-d)$ and chronically (e, $f$ ) with $d$ TC. $a$, Scatter plot showing the intervals between spontaneous bursting episodes in a st. 29 embryo that, under control conditions, burst every $5.6 \pm 2.1$ min (mean \pm SD; $n=10)$. The addition of $d \mathrm{TC}$ transiently blocked bursting, which then resumed at a lower frequency; the time between episodes was $14.4 \pm 1.29$ min (mean $\pm \mathrm{SD} ; n=9)$. $b$, Scatter plot showing the interval between spontaneous bursting episodes in a st. 32 embryo; under control conditions an episode occurred every $8.2 \pm 3.03$ min (mean $\pm \mathrm{SD} ; n=8$ ), whereas after the addition of $d$ TC only a single episode occurred after 82 min and none occurred with an additional $50 \mathrm{~min}$. $c$, In the same embryo as in $a$, the entire bursting episode before $d$ TC is shown (top pair of traces; femorotibialis and sartorius, respectively); a single burst is indicated by a bracket. The bottom pair of traces shows the burst structure of spontaneous episodes after the recovery of bursting in the continued presence of $5 \times 10^{-6} \mathrm{M} d \mathrm{TC}$. Note the changes in burst structure: increased amplitude of the first two bursts and the decrease in the third burst and its time of appearance (compare solid arrows). $d$, The structure and length of the episode (the same embryo as in $b$ ) are altered from control (top pair of traces; femorotibialis and sartorius, respectively) after the addition of $5 \times 10^{-6} \mathrm{M} d \mathrm{TC}$ (Figure legend continues) 


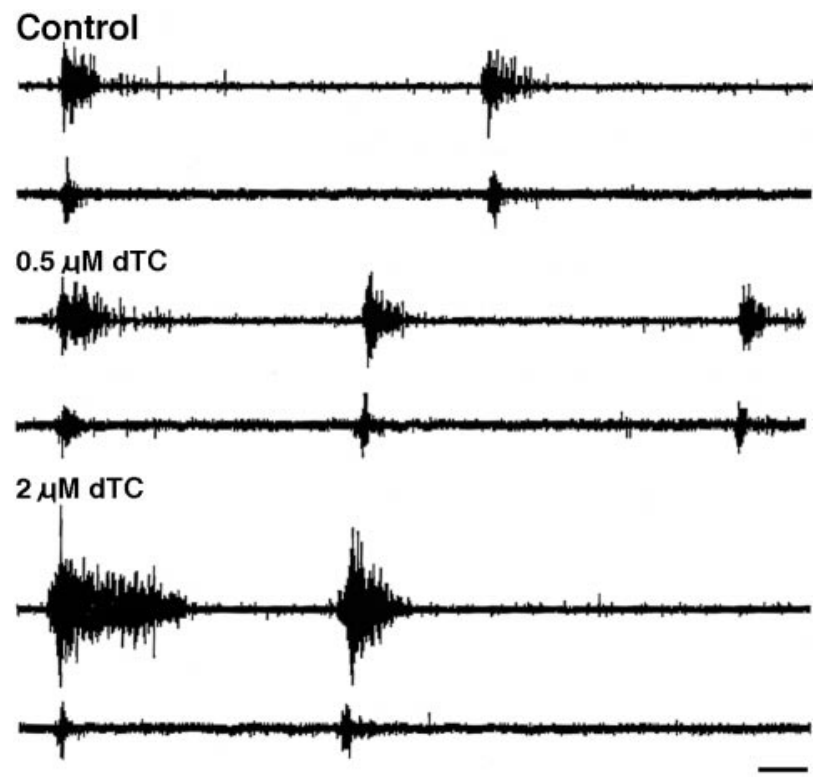

Figure 7. Dose-dependent alterations in a spontaneous bursting episode produced by $d \mathrm{TC}$. In an isolated cord preparation of a st. 28 embryo, $5 \times$ $10^{-7} \mathrm{M} d \mathrm{TC}$, a dose that does not block the NMJ, induces the appearance of an extra third burst. $d \mathrm{TC}\left(2 \times 10^{-6} \mathrm{M}\right)$ alters the burst structure and increases burst length and amplitude, especially in the femorotibialis (top trace in each pair) and sartorius (bottom trace of each pair) as compared with control. At $5 \times 10^{-7} \mathrm{M} d \mathrm{TC}$, the third burst no longer occurs, but the first bursts are increased in amplitude. Calibration bar (for all six traces), $1 \mathrm{sec}$.

the presence of $d \mathrm{TC}$ also may explain the result of Hory-Lee and Frank (1995), who reported that subparalytic doses of $d$ TC could both increase intramuscular nerve branching and promote motoneuron survival. As shown in Figure 7, at st. 28 just as motoneurons begin to grow into their target muscle, $5 \times 10^{-7} \mathrm{M}$ $d \mathrm{TC}$, a dose that does not block the neuromuscular junction and that also has no effect on the frequency of motoneuron bursting episodes, elicits an extra burst in each episode without affecting the burst structure. At a higher dose of $2 \times 10^{-6} \mathrm{M} d \mathrm{TC}$, both the amplitude and length of the burst is affected, which is even more extreme at $1 \times 10^{-5} \mathrm{M} d \mathrm{TC}$ (latter not shown).

On the other hand, $d \mathrm{TC}$ reduced, to a varying extent depending on the developmental stage, the frequency of spontaneous bursting episodes. However, at no stage did $d \mathrm{TC}$ prevent the ability of descending input to evoke a robust bursting episode. Thus, activation of bursting in ovo either by descending input or by sensory input appears likely. To understand better how cord circuits would be affected by chronic $d \mathrm{TC}$ application, we treated several embryos in ovo for 1-2 d and then made isolated cord preparations in the continued presence of $5 \times 10^{-6} \mathrm{M} d \mathrm{TC}$.
As shown by the example in Figure 6e, the st. 30 embryo, chronically treated with $d \mathrm{TC}$, produced spontaneous bursting episodes consisting of well formed high-amplitude bursts, similar to what would have occurred in a control embryo. As in the acutely treated $d \mathrm{TC}$ embryos, however, the frequency of bursting episodes was reduced and more irregular in timing, with a mean inter-episode interval of $17.4 \pm 11.3 \min ($ mean $\pm \mathrm{SD} ; n=7$ ) as compared with $4.2 \pm 0.13$ min (mean $\pm \mathrm{SD} ; n=7$ ) for the control. Similar bursting episodes also could be evoked by stimulation of the descending input (see Fig. 6e, bottom pair of traces). Thus, in summary, although we cannot be certain of the precise frequency with which bursting occurs in the $d$ TC-treated embryos in ovo, the overall effect is clearly opposite from muscimol, which blocks or greatly attenuates bursting under all circumstances.

As described above, we found that an injection of endo-N to remove PSA from the limb of an embryo during chronic $d$ TC treatment partially reversed the effect of dTC on both motoneuron survival and intramuscular nerve branching. This might have occurred because endo-N was able to prevent the $d$ TC-induced increased expression of PSA, which has been postulated to promote increased branching (Landmesser et al., 1990). The reduced branching in turn might have contributed to reduced motoneuron survival. However, it was necessary to determine whether endo-N also might be acting by altering in some way the effect of $d \mathrm{TC}$ on spontaneous motoneuron activity. Although endo-N did not reverse the $d$ TC-induced motility blockade and thus peripheral NMJ blockade (present study), no studies have tested its effect on motoneuron activity in embryos treated chronically with $d \mathrm{TC}$.

To assay this, we chronically treated embryos with $d \mathrm{TC}$ and removed PSA from only one limb as we had done earlier. We then dissected such embryos in the continued presence of $5 \times 10^{-6} \mathrm{M}$ $d \mathrm{TC}$ and recorded spontaneous bursting activity from both the endo-N-injected side and the contralateral limb (the latter serving as a control).

In a neurogram recording (Fig. $6 f$ ) comparing the femorotibialis muscle nerve on the left side (noninjected hindlimb) and the right side (injected hindlimb), we found that both muscles were activated in complete synchrony and that there were no differences in burst structure. The frequency of bursting episodes in this dually treated embryo $(5.3 \pm 7.8$ min; mean $\pm \mathrm{SD} ; n=9)$ was irregular, because we observed intervals ranging from 1.4 to 26 min. Such irregular bursting was common after chronic $d \mathrm{TC}$ treatment, and on washout of $d$ TC the interval from this embryo became faster and more regular $(4.9 \pm 0.6$ min; mean $\pm \mathrm{SD} ; n=$ 16), similar to that of the control embryo shown in Figure $6 a$ $(5.6 \pm 2.1 \mathrm{~min}$; mean $\pm \mathrm{SD} ; n=10)$. We also observed the effects of acute $d$ TC application on a st. 29 chronically treated endo-N embryo (Fig. $6 f$, lower pair of traces; femorotibialis and sartorius muscle nerve recordings, respectively). Although this embryo exhibited a burst structure and interepisode interval (see Fig. $5 a$

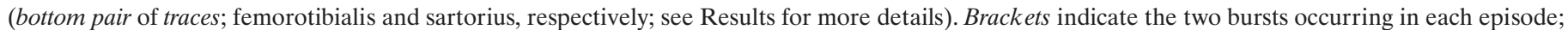

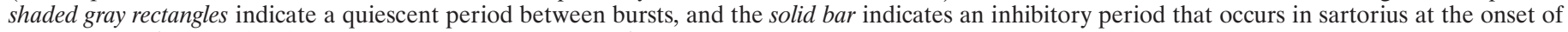

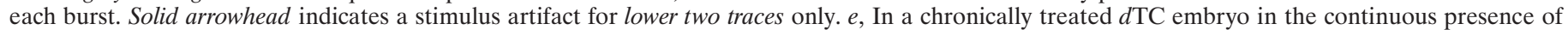

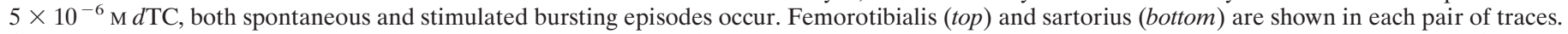

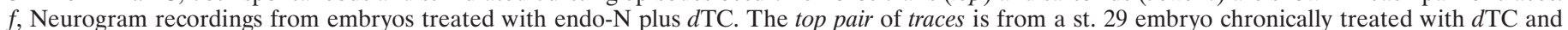

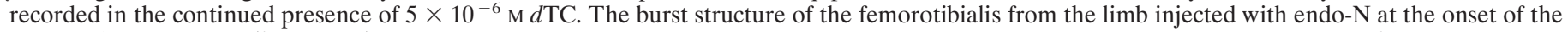

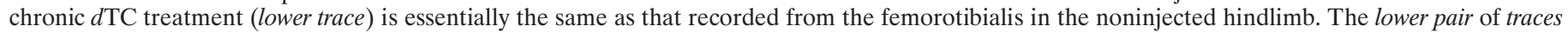

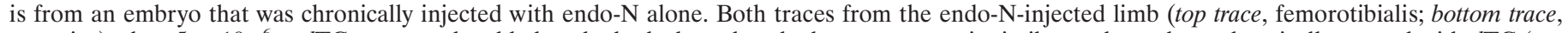

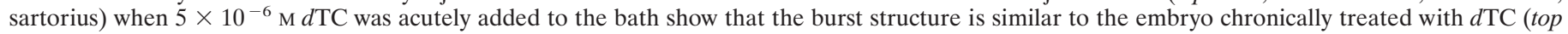

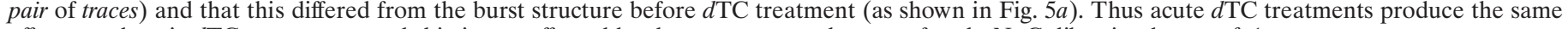
effects as chronic $d$ TC treatments, and this is not affected by the presence or absence of endo-N. Calibration bars: $c-f, 1$ sec. 


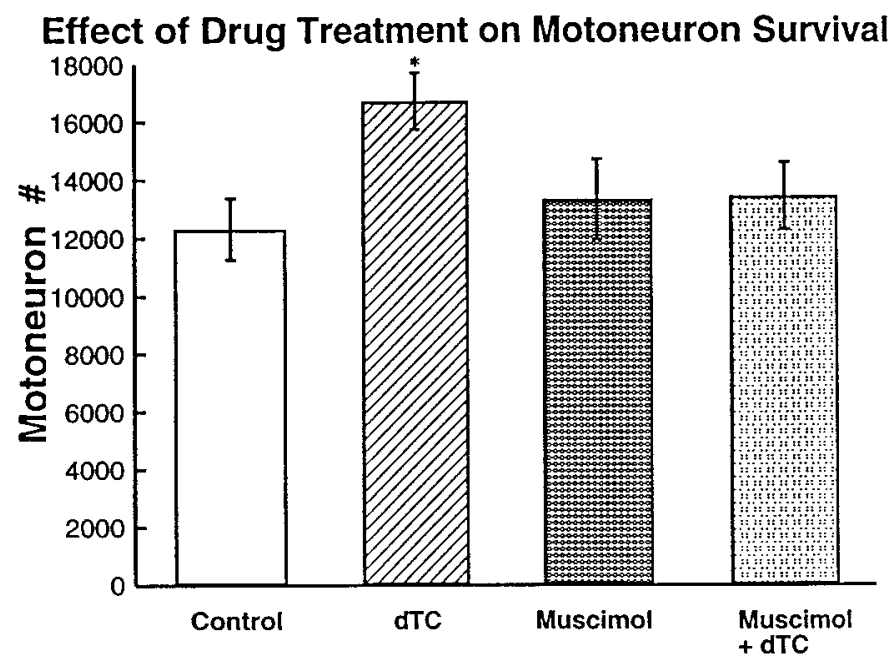

Figure 8. Effect of combined muscimol and $d \mathrm{TC}$ treatment during the cell death period on motoneuron survival as shown from counts of the LMC at the end of the naturally occurring period of cell death (st. 36). The number of motoneurons in the dual treatment is not significantly different from those of control but is significantly different from those of $d$ TC treatment alone (by $t$ test: $p=8.7 \times 10^{-5}$ for one-tailed and $p=$ $1.7 \times 10^{-4}$ for two tailed; $n=3$ for each drug treatment except muscimol alone, which is $n=6$ ).

and accompanying text) similar to the control, on the addition of $d$ TC $\left(5 \times 10^{-6} \mathrm{M}\right)$ the structure changed (Fig. $6 f$, lower pair of traces) to that seen previously in the presence of $d \mathrm{TC}$ (compare with Fig. $6 c, e$ ). Overall then, in ovo injections of endo-N do not alter bursting from control, nor do they alter the effects on bursting produced by either the acute or chronic application of $d \mathrm{TC}$.

\section{Effect of combined muscimol and dTC treatment}

To test whether the different effects the two drugs had on motoneuron survival might be explained by their different effects on motoneuron bursting activity (i.e., $d$ TC possibly enhancing and muscimol blocking spontaneous activity), we first determined the effect of combined muscimol and $d \mathrm{TC}$ drug treatments on electrical activity. In the isolated spinal cord preparation we found that, in the combined presence of $5 \times 10^{-6} \mathrm{M}$ muscimol and $d \mathrm{TC}$, no spontaneous bursts occurred, nor could they be elicited by stimulation of the rostral cord at st. 29 or 32 (data not shown). Thus, although $d \mathrm{TC}$ was present and potentially acting at both peripheral and central sites, the simultaneous presence of muscimol prevented motoneuron bursting activity. We then determined how chronic application of the two drugs in ovo affected motoneuron survival.

The results of the combined $d \mathrm{TC}$ and muscimol treatment during the cell death period on motoneuron survival are shown in Figure 8. Interestingly, the total lumbar motoneuron cell counts in this combined treatment were very similar to muscimol treatment alone; neither was significantly different from control. These results sharply contrast with the $d \mathrm{TC}$ treatment alone, in which there was a $36 \%$ increase in motoneuron survival over control. Thus, it appears that the effects of muscimol dominate over the influence of $d \mathrm{TC}$ on affecting cell survival.

Additionally, we assessed the effect of the combined muscimol and $d \mathrm{TC}$ treatment on intramuscular nerve branching patterns. The branching pattern in the combined treatment clearly differed
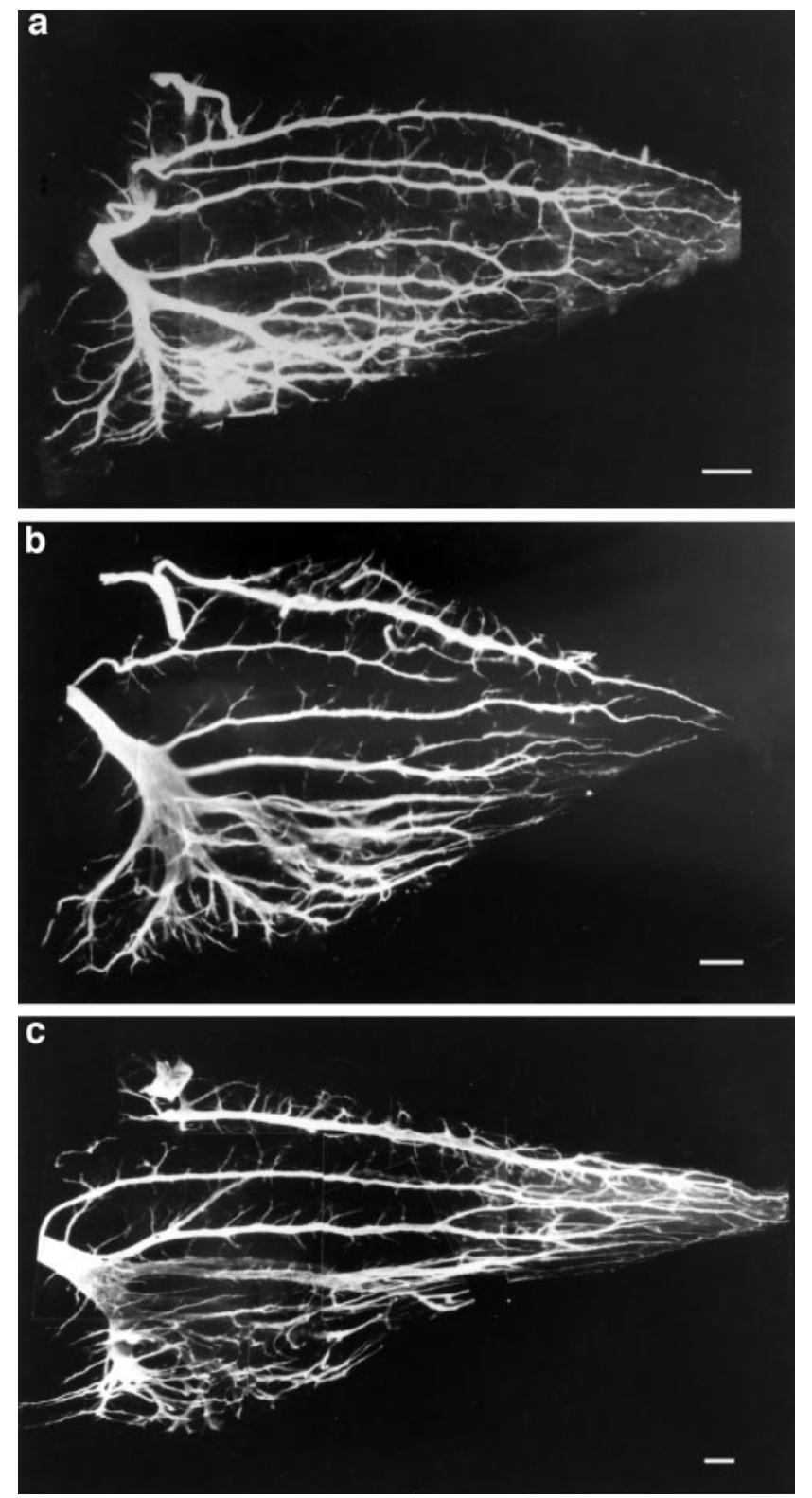

Figure 9. Effect of combined muscimol and $d \mathrm{TC}$ treatment during the cell death period on the intramuscular nerve branching pattern seen in st. 34 chick IFIB muscle. $a$, Muscimol treatment alone. $b$, Combined muscimol and $d \mathrm{TC}$ treatment. $c, d \mathrm{TC}$ treatment alone. Although there was some increase in branching in the combined treatment, when compared with muscimol alone it was considerably less than that produced by $d \mathrm{TC}$ treatment alone. Scale bars: $a, b, 15 \mu \mathrm{m} ; c, 10 \mu \mathrm{m}$.

from that of $d \mathrm{TC}$ alone; specifically, the fast region was not so highly defasciculated and branched (Fig. $9 b$ ), nor was there a large increase in side branch number in the slow region. However, there did appear to be some increase in branching over that of muscimol alone.

In summary, the effects of the combined treatment on the spontaneous bursting activity and motoneuron cell survival are similar to the effect of muscimol alone. Although $d \mathrm{TC}$ was present, it was not able to prevent the blockade of spontaneous bursting caused by muscimol; in turn, we did not observe the large increase in survival or in intramuscular nerve branching that $d \mathrm{TC}$ treatment alone elicits. 


\section{DISCUSSION}

The present studies were designed to (1) explore why in vivo blockade of neuromuscular activity with $d$ TC rescues motoneurons from naturally occurring cell death as shown earlier (Pittman and Oppenheim, 1978), and (2) to test further the hypothesis (Dahm and Landmesser, 1988, 1991; Oppenheim, 1989) that the $d$ TC-induced increase in intramuscular nerve branching was critical to this rescue. We found that, although the $\mathrm{GABA}_{\mathrm{A}}$ agonist muscimol indirectly blocked neuromuscular activity by suppressing the spontaneous bursting of motoneurons centrally, it did not rescue motoneurons from cell death. Thus, consistent with earlier observations (Oppenheim et al., 1989), we conclude that preventing the activation of the NMJ and any downstream consequences alone are insufficient to rescue motoneurons.

A novel finding was that, early in the motoneuron cell death period, $d$ TC not only blocked the neuromuscular junction but also had strong central effects on motoneuron bursting activity, which were the opposite of muscimol. We propose that the different central effects of muscimol and $d \mathrm{TC}$, by their direct actions on the activity of cord circuits and motoneurons and/or by indirectly affecting intramuscular nerve branching, may explain their differential effects on motoneuron survival. Additionally, because muscimol had no effect on naturally occurring motoneuron death and because it did block both spontaneous motoneuron activity and the ability of descending input to evoke such activity, we conclude that motoneuron activity, per se, and any downstream consequences are not essential for the normal process of motoneuron cell death. This is a novel finding, because none of the studies assaying motility has assessed motoneuron activity directly.

One possible outcome of our studies might have been an uncoupling of alterations in intramuscular nerve branching from motoneuron survival, casting doubt on the hypothesis that increased branching and synapse formation were critical to enhanced survival (Dahm and Landmesser, 1988, 1991; Oppenheim, 1989). However, in contrast to this possibility, we found a good correlation between intramuscular nerve branching and survival. Thus, removal of PSA with endo-N partially prevented the $d \mathrm{TC}$-induced increase in both intramuscular nerve branching and motoneuron survival. Similarly, the presence of muscimol prevented the $d \mathrm{TC}$-induced enhancement of motoneuron survival and greatly reduced the $d \mathrm{TC}$-induced increase in branching. Other observations are consistent with this hypothesis: removal of PSA alone reduces both branching and motoneuron survival (Tang and Landmesser, 1993); nicotine and decamethonium produce activity blockade but do not increase motoneuron survival or synapse formation (Oppenheim et al., 1989). Excitation contraction coupling mutants in both the mouse ( $m d g / m d g$; Rieger and Pinçon-Raymond, 1981; Powell et al., 1984; Oppenheim et al., 1986; Houeneou et al., 1990) and the chick (cn/cn; Oppenheim et al., 1997) increase both branching and survival. Even subparalytic doses of $d \mathrm{TC}$ that result in increased survival also increase branching (Hory-Lee and Frank, 1995).

Despite such correlation, the effects of $d \mathrm{TC}$ on motoneuron survival could result in part from its central effects. Although several previous studies have demonstrated the presence of nicotinic receptors within the spinal cord (Renshaw et al., 1993; Renshaw and Goldie, 1996), our observations are the first to show that blocking nicotinic receptors actually alters the functional activation of motoneurons during the cell death period. Furthermore, the effect of cholinergic antagonists, such as $d \mathrm{TC}$, on motoneuron activity was, in general, opposite to the effects of muscimol, which did not enhance survival. One possibility is that enhanced activation of motoneurons may influence their survival directly, possibly by altering $\left[\mathrm{Ca}^{2+}\right]_{i}$; (Vijayaraghavan et al., 1992; Zhang et al., 1994). This, in turn, could lead to alterations in signaling cascades and gene expression (for review, see Ghosh and Greenberg, 1995; Finkbeiner and Greenberg, 1996; Ginty, 1997; Berridge, 1998) that could interfere directly with the cell death process (for review, see Henderson, 1996). It is interesting then that we observed that subparalytic doses of $d \mathrm{TC}$, which rescues motoneurons (Hory-Lee and Frank, 1995), also enhances motoneuron activity over control levels. Also consistent with this hypothesis is our observations that muscimol, when applied alone, prevented both motoneuron activity and increased motoneuron survival. Additionally, muscimol, which suppressed motoneuron activity in the presence of $d \mathrm{TC}$, also prevented the effects of $d$ TC on survival. However, opposing such a direct effect of $d \mathrm{TC}$ as the sole explanation for increased motoneuron survival was the finding that PSA removal was able to attenuate significantly the effect of $d \mathrm{TC}$ on survival, although $d \mathrm{TC}$ was present and able to act at both central and peripheral sites. We also demonstrated that endo-N did not produce this effect by acting centrally to alter the effects of $d \mathrm{TC}$ on spontaneous motoneuron bursting.

Another possibility is that $d \mathrm{TC}$-induced alterations in motoneuron activation could affect survival by altering motoneuron uptake of trophic molecules, either centrally or peripherally. Although it is known that the periphery can regulate the survival of motoneurons (Hamburger, 1958; Hollyday and Hamburger, 1976; Oppenheim et al., 1978) and in vitro studies have identified candidate trophic molecules (Oppenheim, 1996; Calderó et al., 1998), it is not clear how trophic molecules actually affect motoneuron survival in vivo or how $d \mathrm{TC}$ might influence the process. One possibility is that $d \mathrm{TC}$ could result in the enhanced release of trophic molecules centrally or peripherally via activity-dependent mechanisms (Ghosh et al., 1994; Boulanger and Poo, 1999) (for review, see Thoenen, 1995). Second, $d$ TC could cause increased cell surface expression of neurotrophin receptors (depolarization of cultured DRG neurons does lead to such enhanced expression; Meyer-Franke et al., 1998). Third, increases in peripheral branching, as discussed above, could result in increased uptake of trophic factors (Dahm and Landmesser, 1988; DiStefano et al., 1992; Yan et al., 1993) (for review, see Fitzsimonds and Poo, 1998). Although it should be possible to compare Trk receptor expression on motoneurons chronically treated with $d$ TC versus muscimol, existing methodologies do not have sufficient resolution to detect possible alterations in either the release or uptake of neurotrophins.

An important question to resolve is whether $d \mathrm{TC}$ is simply acting pharmacologically to short-circuit the normal process of motoneuron cell death, or, alternatively, whether it is altering a variable that is used physiologically to regulate naturally occurring cell death. In this regard, it is useful to compare the current findings with other experimental situations that rescue motoneurons from cell death. In the crooked neck dwarf mutant $(\mathrm{cn} / \mathrm{cn})$, chick motoneurons are activated normally, as is neuromuscular transmission, and muscle fibers exhibit action potentials. However, because of an excitation-coupling defect, contraction does not occur (Oppenheim et al., 1997). Why are motoneurons rescued in this situation and in the $m d g / m d g$ mutant mouse (Oppenheim et al., 1986; Houeneou et al., 1990)? One possibility is that $\mathrm{Ca}^{2+}$ released from internal muscle fiber stores after excitationcontraction coupling normally inhibits the production and/or re- 
lease of sprouting factors or neurotrophins. When this fails to occur in the mutant, motoneuron survival could be enhanced because of the increased supply of trophins. Alternatively, increased release of sprouting factors could enhance access to neurotrophins by increasing branching, which is, in fact, increased in the $\mathrm{cn} / \mathrm{cn}$ mutant. However, contraction and release of $\mathrm{Ca}^{2+}$ from internal muscle cell stores also would be blocked in the muscimol treatment, which does not result in increased survival.

One way of reconciling these and other observations (Oppenheim et al., 1986; Houeneou et al., 1990, 1991; Oppenheim et al., 1997 ) is to propose that some event triggered by target inactivity (such as the increased release of sprouting factors/neurotrophins) needs to be coupled to normally active motoneurons. Motoneuron bursting activity might be required either for the uptake of such factors or for appropriately responding to them (see Boulanger and Poo, 1999); thus enhanced survival would occur in cases in which motoneurons were active $(d \mathrm{TC})$ but not when they were inactive (muscimol).

Motoneuron activity also could alter intramuscular nerve branching by regulating the expression of adhesion molecules on nerve or muscle. In both spinal cord (O'Donovan et al., 1994) and retina (Meister et al., 1991; Catsicas et al., 1998), episodes of spontaneous activity result in periodic increases in $\left[\mathrm{Ca}^{2+}\right]_{i}$, and the pattern of such oscillations would have differed with the drug treatments we performed. In this regard, it is interesting that the expression of the neural adhesion molecule L1, which can mediate both the growth and the fasciculation of axons (Landmesser et al., 1988; Burden-Gulley et al., 1997), is sensitive to the pattern of electrical activity (Itoh et al., 1995). Polysialylation of NCAM, which has strong effects on intramuscular nerve branching (Landmesser et al., 1990; present results) also is regulated by activity via changes in $\left[\mathrm{Ca}^{2+}\right]_{\mathrm{i}}$ (Rafuse and Landmesser, 1996; Brusés and Rutishauser, 1998). Alternately, exposure to different patterns of electrical activity can affect how axons regulate $\left[\mathrm{Ca}^{2+}\right]_{\mathrm{i}}$ (Lnenicka et al., 1998), and $\mathrm{Ca}^{2+}$ transients can affect directly the growth and/or retraction of neurites (Gomez and Spitzer, 1999). Finally, ACh released by the activity from motoneuron growth cones could bind to axonal nicotinic receptors and affect growth by altering $\left[\mathrm{Ca}^{2+}\right]_{\mathrm{i}}$ or other consequences of $\mathrm{AChR}$ activation (see Pugh and Berg, 1994). It will be important now to determine which downstream consequences of motoneuron activity are modulating both intramuscular axonal branching and motoneuron survival.

\section{REFERENCES}

Abercrombie M (1946) Estimation of nuclear population from microtome sections. Anat Rec 94:239-247.

Acheson A, Sunshine JL, Rutishauser U (1991) NCAM polysialic acid can regulate both cell-cell and cell-substrate interactions. J Cell Biol 114:143-153.

Antal M, Berki AC, Horvàth L, O’Donovan MJ (1994) Developmental changes in the distribution of gamma-aminobutyric acidimmunoreactive neurons in the embryonic chick lumbosacral spinal cord. J Comp Neurol 343:228-236.

Bekoff A, Stein PSG, Hamburger V (1975) Coordinated motor output in the hindlimb of the 7-day chick embryo. Proc Natl Acad Sci USA 72:1245-1248.

Berridge MJ (1998) Neuronal calcium signaling. Neuron 21:13-26.

Boulanger L, Poo M (1999) Presynaptic depolarization facilitates neurotrophin-induced synaptic potentiation. Nat Neurosci 2:346-351.

Brusés JL, Rutishauser U (1998) Regulation of neural cell adhesion molecule polysialylation: evidence for nontranscriptional control and sensitivity to an intracellular pool of calcium. $\mathrm{J}$ Cell Biol 140:1177-1186.

Burden-Gulley SM, Pendergast M, Lemmon V (1997) The role of cell adhesion molecule L1 in axonal extension, growth cone motility, and signal transduction. Cell Tissue Res 290:415-422.

Calderó J, Prevette D, Mei X, Oakley RA, Li L, Milligan C, Houenou L, Burek M, Oppenheim RW (1998) Peripheral target regulation of the development and survival of spinal sensory and motoneurons in the chick embryo. J Neurosci 18:356-370.

Catsicas M, Bonness V, Becker D, Mobbs P (1998) Spontaneous Ca ${ }^{2+}$ transients and their transmission in the developing chick retina. Curr Biol 8:283-286.

Chub N, O’Donovan MJ (1998) Blockade and recovery of spontaneous rhythmic activity after application of neurotransmitter antagonists to spinal networks of the chick embryo. J Neurosci 18:294-306.

Dahm LM, Landmesser LT (1988) The regulation of intramuscular nerve branching during normal development and following activity blockade. Dev Biol 130:621-644.

Dahm LM, Landmesser LT (1991) The regulation of synaptogenesis during normal development and following activity blockade. J Neurosci 11:238-255.

Ding R, Jansen KS, Laing NG, Tønnesen H (1983) The innervation of skeletal muscles in chickens curarized during early development. J Neurocytol 12:887-919.

DiStefano P, Friedman B, Radziejewski C, Alexander C, Boland P, Schick C, Lindsay R, Wiegand S (1992) The neurotrophins BDNF, NT-3, and NGF display distinct patterns of retrograde axonal transport in peripheral and central neurons. Neuron 8:983-993.

Finkbeiner S, Greenberg ME (1996) $\mathrm{Ca}^{2+}$-dependent routes to Ras: mechanisms for neuronal survival, differentiation, and plasticity? Neuron 16:233-236.

Fitzsimonds RM, Poo MM (1998) Retrograde signaling in the development and modification of synapses. Physiol Rev 78:143-170.

Fredette BJ, Landmesser LT (1991) Relationship of primary and secondary myogenesis to fiber type development in embryonic chick muscle. Dev Biol 143:1-18.

Ghosh A, Greenberg ME (1995) Calcium signaling in neurons: molecular mechanisms and cellular consequences. Science 268:239-247.

Ghosh A, Carnahan J, Greenberg ME (1994) Requirement for BDNF in activity-dependent survival of cortical neurons. Science 263:1618-1623.

Ginty DD (1997) Calcium regulation of gene expression: isn't that spatial? Neuron 18:183-186.

Gomez TM, Spitzer NC (1999) In vivo regulation of axon extension and pathfinding by growth-cone calcium transients. Nature 397:350-354.

Hamburger V (1958) Regression versus peripheral control of differentiation in motor hypoplasia. Am J Anat 102:365-409.

Hamburger V (1975) Cell death in the development of the lateral motor column of the chick embryo. J Comp Neurol 160:535-546.

Hamburger V (1977) The developmental history of the motor neuron. Neurosci Res Program Bull [Suppl] 15:iii-37.

Hamburger V, Balaban M (1963) Observations and experiments on spontaneous rhythmical behavior in the chick embryo. Dev Biol 7:533-545.

Hamburger V, Hamilton HL (1951) A series of normal stages in the development of the chick embryo. J Morphol 88:49-82.

Hamburger V, Balaban M, Oppenheim R, Wenger E (1965) Periodic motility of normal and spinal chick embryos between 8 and 17 days of incubation. J Exp Zool 159:1-14.

Henderson CE (1996) Programmed cell death in the developing nervous system. Neuron 17:579-585.

Hollyday M, Hamburger V (1976) Reduction of the naturally occurring motor neuron loss by enlargement of the periphery. J Comp Neurol 170:311-320.

Hory-Lee F, Frank E (1995) The nicotinic blocking agents $d$-tubocurare and $\alpha$-bungarotoxin save motoneurons from naturally occurring death in the absence of neuromuscular blockade. J Neurosci 15:6453-6460.

Houeneou LJ, Pinçon-Raymond M, Garcia L, Harris AJ, Rieger F (1990) Neuromuscular development following tetrodotoxin-induced inactivity in mouse embryos. J Neurobiol 21:1249-1261.

Houeneou LJ, McManaman JL, Prevette D, Oppenheim RW (1991) Regulation of putative muscle-derived neurotrophic factors by muscle activity and innervation: in vivo and in vitro studies. J Neurosci 11:2829-2837.

Itoh K, Stevens B, Schachner M, Fields RD (1995) Regulated expression of the neural cell adhesion molecule L1 by specific patterns of neural impulses. Science 270:1369-1372. 
Landmesser L (1978a) The distribution of motoneurones supplying chick hind limb muscles. J Physiol (Lond) 284:371-389.

Landmesser L (1978b) The development of motor projection patterns in the chick hind limb. J Physiol (Lond) 284:391-414.

Landmesser L (1992) The relationship of intramuscular nerve branching and synaptogenesis to motoneuron survival. J Neurobiol 23:1131-1139.

Landmesser LT, O'Donovan MJ (1984) Activation patterns of embryonic chick hind limb muscles recorded in ovo and in an isolated spinal cord preparation. J Physiol (Lond) 347:189-204.

Landmesser LT, Szente M (1986) Activation patterns of embryonic chick hind limb muscles following blockade of activity and motoneurone cell death. J Physiol (Lond) 380:157-174.

Landmesser L, Dahm L, Schultz K, Rutishauser U (1988) Distinct roles for adhesion molecules during innervation of embryonic chick muscle. Dev Biol 130:645-670.

Landmesser L, Dahm L, Tang J, Rutishauser U (1990) Polysialic acid as a regulator of intramuscular nerve branching during embryonic development. Neuron 4:655-667.

Lnenicka GA, Arcaro KF, Calabro JM (1998) Activity-dependent development of calcium regulation in growing motor axons. J Neurosci 18:4966-4972.

Meister M, Wong ROL, Baylor DA, Shatz CJ (1991) Synchronous bursts of action potentials in ganglion cells of the developing mammalian retina. Science 252:939-943.

Meyer-Franke A, Wilkinson GA, Kruttgen A, Hu M, Munro E, Hanson Jr MG, Reichardt LF, Barres BA (1998) Depolarization and cAMP elevation rapidly recruit TrkB to the plasma membrane on CNS neurons. Neuron 21:681-693.

Milner LD, Landmesser LT (1999) Cholinergic and GABAergic inputs drive patterned spontaneous motoneuron activity prior to target contact. J Neurosci 19:3007-3022.

Milner LD, Rafuse VF, Landmesser LT (1998) Selective fasciculation and divergent pathfinding decisions of embryonic chick motor axons projecting to fast and slow muscle regions. J Neurosci 18:3297-3313.

O'Donovan MJ, Landmesser LT (1987) The development of hindlimb motor activity studied in the isolated spinal cord of the chick embryo. J Neurosci 7:3256-3264.

O'Donovan MJ, Ho S, Yee W (1994) Calcium imaging of rhythmic network activity in the developing spinal cord of the chick embryo. J Neurosci 14:6354-6369.

Oppenheim R (1975) The role of supraspinal input in embryonic motility: a re-examination in the chick J Comp Neurol 160:37-50.

Oppenheim RW (1989) The neurotrophic theory and naturally occurring motoneuron death. Trends Neurosci 12:252-255.

Oppenheim RW (1991) Cell death during development of the nervous system. Annu Rev Neurosci 14:453-501.

Oppenheim RW (1996) Neurotrophic survival molecules for motoneurons: an embarrassment of riches. Neuron 17:195-197.

Oppenheim RW, Chu-Wang IW (1977) Spontaneous cell death of motoneurons following peripheral innervation in the chick embryo. Brain Res 125:154-160.

Oppenheim RW, Chu-Wang IW, Maderdrut JL (1978) Cell death of motoneurons in the chick embryo spinal cord. III. The differentiation of motoneurons prior to their induced degeneration following limb-bud removal. J Comp Neurol 177:87-112.

Oppenheim RW, Houenou L, Pinçon-Raymond M, Powell JA, Rieger F, Standish LJ (1986) The development of motoneurons in the embryonic spinal cord of the mouse mutant, muscular dysgenesis $(m d g / m d g)$ : survival, morphology, and biochemical differentiation. Dev Biol 114:426-436.

Oppenheim RW, Bursztajn S, Prevette D (1989) Cell death of motoneurons in the chick embryo spinal cord. XI. Acetylcholine receptors and synaptogenesis in skeletal muscle following the reduction of motoneuron death by neuromuscular blockade. Development 107:331-341.

Oppenheim RW, Prevette D, Houenou LJ, Pinçon-Raymond M, Dimitriadou V, Donevan A, O'Donovan M, Wenner P, McKemy DD, Allen PD (1997) Neuromuscular development in the avian paralytic mutant crooked neck dwarf $(\mathrm{cn} / \mathrm{cn})$ : further evidence for the role of neuromuscular activity in motoneuron survival. J Comp Neurol 381:353-372.
Owens DF, Boyce LH, Davis MBE, Kriegstein AR (1996) Excitatory GABA responses in embryonic and neonatal cortical slices demonstrated by gramicidin perforated-patch recordings and calcium imaging. J Neurosci 16:6414-6423.

Pittman RH, Oppenheim RW (1978) Neuromuscular blockade increases motoneurone survival during normal cell death in the chick embryo. Nature 271:364-366.

Pittman RH, Oppenheim RW (1979) Cell death in the chick embryo spinal cord. IV. Evidence that a functional neuromuscular interaction is involved in the regulation of naturally occurring cell death and the stabilization of synapses. J Comp Neurol 187:425-446.

Powell JA, Rieger F, Blondet B, Dreyfus P, Pinçon-Raymond M (1984) Distribution and quantification of ACh receptors and innervation in diaphragm muscle of normal and $m d g$ mouse embryos. Dev Biol 101:168-180.

Pugh PC, Berg DK (1994) Neuronal acetylcholine receptors that bind $\alpha$-bungarotoxin mediate neurite retraction in a calcium-dependent manner. J Neurosci 14:889-896.

Rafuse VF, Landmesser L (1996) Contractile activity regulates isoform expression and polysialylation of NCAM in cultured myotubes: involvement of $\mathrm{Ca}^{2+}$ and protein kinase C. J Cell Biol 132:969-983.

Rafuse VF, Milner LD, Landmesser L (1996) Selective innervation of fast and slow muscle during early chick neuromuscular development. J Neurosci 16:6864-6877.

Reitzel JL, Maderdrut JL, Oppenheim RW (1979) Behavioral and biochemical analysis of GABA-mediated inhibition in the early chick embryo. Brain Res 172:487-504.

Renshaw GMC, Goldie R (1996) Neuronal bungarotoxin displaces $\left[{ }^{125} \mathrm{I}\right]$ $\alpha$-bungarotoxin binding at the neuromuscular junction as well as to the spinal cord during embryogenesis. Brain Res 709:316-318.

Renshaw G, Rigby P, Self G, Lamb A, Goldie R (1993) Exogenously administered $\alpha$-bungarotoxin binds to embryonic chick spinal cord: implications for the toxin-induced arrest of naturally occurring motoneuron death. Neuroscience 53:1163-1172.

Rieger F, Pinçon-Raymond M (1981) Muscle and nerve in muscular dysgenesis in the mouse at birth: sprouting and multiple innervation. Dev Biol 87:85-101.

Rohrbough J, Spitzer NC (1996) Regulation of intracellular $\mathrm{Cl}^{-}$levels by $\mathrm{Na}^{+}$-dependent $\mathrm{Cl}^{-}$cotransport distinguishes depolarizing from hyperpolarizing $\mathrm{GABA}_{\mathrm{A}}$ receptor-mediated responses in spinal neurons. J Neurosci 16:82-91.

Sernagor E, Chub N, Ritter A, O’Donovan MJ (1995) Pharmacological characterization of the rhythmic synaptic drive onto lumbosacral motoneurons in the chick embryo spinal cord. J Neurosci 15:7452-7464.

Sholomenko GN, O’Donovan MJ (1995) Development and characterization of pathways descending to the spinal cord in embryonic chick. J Neurophysiol 73:1223-1233.

Tanaka H, Landmesser LT (1986) Cell death of lumbosacral motoneurons in chick, quail, and chick-quail chimera embryos: a test of the quantitative matching hypothesis of neuronal cell death. J Neurosci 6:2889-2899.

Tang J, Landmesser L (1993) Reduction of intramuscular nerve branching and synaptogenesis is correlated with decreased motoneuron survival. J Neurosci 13:3095-3103.

Thoenen H (1995) Neurotrophins and plasticity. Science 270:593-598.

Vijayaraghavan S, Pugh PC, Zhang Z, Rathouz MM, Berg DK (1992) Nicotinic receptors that bind $\alpha$-bungarotoxin on neurons raise intracellular free $\mathrm{Ca}^{2+}$. Neuron 8:353-362.

Wu W, Ziskind-Conhaim L, Sweet MA (1992) Early development of glycine- and GABA-mediated synapses in rat spinal cord. J Neurosci 12:3935-3945.

Yan Q, Elliott JL, Matheson C, Sun J, Zhang L, Mu X, Rex KL, Snider WD (1993) Influences of neurotrophins on mammalian motoneurons in vivo. J Neurobiol 24:1555-1577.

Zhang Z, Vijayaraghavan S, Berg DK (1994) Neuronal acetylcholine receptors that bind $\alpha$-bungarotoxin with high affinity function as ligandgated ion channels. Neuron 12:167-177. 